Full-length article submitted to Combustion and Flame

\title{
INTERACTION OF TURBULENT PREMIXED FLAMES WITH COMBUSTION PRODUCTS: ROLE OF STOICHIOMETRY
}

\author{
Bruno Coriton ${ }^{1}$, Jonathan H. Frank ${ }^{1}$ and Alessandro Gomez ${ }^{2 *}$ \\ ${ }^{1}$ Combustion Research Facility, Sandia National Laboratories, Livermore, CA 94551, USA \\ ${ }^{2}$ Yale Center for Combustion Studies, Department of Mechanical Engineering and Materials Science, \\ Yale University, New Haven, CT 06520-8286, USA
}

Full-length article, Submitted to Combustion and Flame onSeptember 11,2015. Revised on February 15, 2016.

${ }^{*}$ Corresponding Author Alessandro Gomez

Department of Mechanical Engineering and Materials Science

Yale University

P.O. Box 208286

New Haven, CT 06520-8286

alessandro.gomez@yale.edu

tel: (203) 432-4384

fax: (203) 432-7654

Page 1 of 49

(C) 2016. This manuscript version is made available under the Elsevier user licensehttp://www.elsevier.com/open-access/userlicense/1.0/ 


\begin{abstract}
Stabilization methods of turbulent flames often involve mixing of reactants with hot products of combustion. The stabilizing effect of combustion product enthalpy has been long recognized, but the role played by the chemical composition of the product gases is typically overlooked. We employ a counterflow system to pinpoint the effects of the combustion product stoichiometry on the structure of turbulent premixed flames under conditions of both stable burning and local extinction. To that end, a turbulent jet of lean-to-rich, $\mathrm{CH}_{4} / \mathrm{O}_{2} / \mathrm{N}_{2}$-premixed reactants at a turbulent Reynolds number of 1050 were opposed to a stream of hot products of combustion that were generated in a preburner. While the combustion product stream temperature was kept constant, its stoichiometry was varied independently from that of the reactant stream, leading to reactant-to-product stratification of relevance to practical combustion systems. The detailed structure of the turbulent flame front was analyzed in two series of experimentsusing laser-induced fluorescence (LIF): joint $\mathrm{CH}_{2} \mathrm{O}$ LIF and $\mathrm{OH}$ LIF measurements and joint $\mathrm{CO}$ LIF and $\mathrm{OH}$ LIF measurements. Results revealed that a decrease in local $\mathrm{CH}_{2} \mathrm{O}+\mathrm{OH}$ and $\mathrm{CO}+\mathrm{OH}$ reaction rates coincide with the depletion of $\mathrm{OH}$ radicals in the vicinity of the combustion product stream. These critical combustion reaction rates were more readily quenched in the presence of products of combustion from a stoichiometric flame, whereas they were favored by lean combustion products. As a result, stoichiometric combustion products contributed to a greater occurrence of local extinction. Furthermore, they limited the capacity of premixed reactants to ignite and of the turbulent premixed flames to stabilize. In contrast, lean and rich combustion products facilitated flame ignition and stability and reduced the rate of local extinction. The influence of the combustion product stream on the turbulent flame front was limited to a zone of approximately two millimeters from the gas mixing layer interface (GMLI) of the product stream. Flame fronts that were separated from the GMLI by larger distances were unaffected by the product stream stoichiometry.
\end{abstract}

Keywords: turbulent counterflow, premixed flames, stratification, extinction 


\section{Nomenclature}

\begin{tabular}{|c|c|}
\hline \multicolumn{2}{|c|}{ Lowercase roman } \\
\hline c & Progress variable \\
\hline$d_{\text {nozzle }}$ & Nozzle separation distance \\
\hline$f_{i}(T)$ & $\begin{array}{l}\text { LIF signal temperature dependence } \\
\left.\text { for species i (i.e., } \mathrm{OH}, \mathrm{CO}, \mathrm{CH}_{2} \mathrm{O}\right)\end{array}$ \\
\hline$k_{\mathrm{CH} 2 \mathrm{O}+\mathrm{OH}}$ & $\mathrm{CH}_{2} \mathrm{O}+\mathrm{OH}$ reaction rate \\
\hline$k_{\mathrm{CH} 2 \mathrm{O}+\mathrm{OH}}^{\mathrm{LIF}}$ & $\begin{array}{l}\text { Product of } \mathrm{CH}_{2} \mathrm{O} \text { LIF and } \mathrm{OH} \text { LIF } \\
\text { signals }\end{array}$ \\
\hline$k_{\mathrm{CH} 2 \mathrm{O}+\mathrm{OH}}^{\max }$ & Peak $\mathrm{CH}_{2} \mathrm{O}+\mathrm{OH}$ reaction rate \\
\hline$k_{\mathrm{CO}+\mathrm{OH}}$ & $\mathrm{CO}+\mathrm{OH}$ reaction rate \\
\hline$k_{\mathrm{CO}+\mathrm{OH}}^{\mathrm{LIF}}$ & $\begin{array}{l}\text { Product of } \mathrm{CO} \text { LIF and OH LIF } \\
\text { signals }\end{array}$ \\
\hline$k_{\mathrm{CO}+O H}^{\max }$ & Peak $\mathrm{CO}+\mathrm{OH}$ reaction rate \\
\hline$l^{\prime}$ & Integral lengthscale \\
\hline$l_{F}$ & Unstrained laminar flame thickness \\
\hline$v^{\prime}$ & RMS axial velocity \\
\hline$x_{n}$ & Flame-normal coordinate \\
\hline$z$ & Axial burner coordinates \\
\hline
\end{tabular}

Uppercase roman

$\mathrm{CH}_{2} \mathrm{O}_{\max }$ Peak $\mathrm{CH}_{2} \mathrm{O}$ LIF signal

$\mathrm{CO}_{\max } \quad$ Peak CO LIF signal

GMLI Gas mixing layer interface
$K a_{t} \quad$ Turbulent Karlovitz number

$K_{\text {bulk }} \quad$ Bulk strain rate

$K_{\text {ext }} \quad$ Extinction strain rate

$K_{i g n} \quad$ Ignition strain rate

$\mathrm{OH}_{\mathrm{o}} \quad \mathrm{OH}$ LIF signal for $\mathrm{x}_{\mathrm{n}}=0$

$R e_{t} \quad$ Turbulent Reynolds number

$S_{L} \quad$ Unstrained laminar flame speed

$S R \quad$ Strain rate for laminar flame calculation

$T \quad$ Temperature

$T_{a d} \quad$ Adiabatic flame temperature

$T_{b} \quad$ Product stream temperature

$V_{\text {bulk }} \quad$ Cold-inlet bulk velocity

\section{Lowercase Greek}

$\varphi_{b} \quad$ Product stream equivalence ratio

$\varphi_{u} \quad$ Fresh reactant equivalence ratio

\section{Uppercase Greek}

$\Delta \quad$ Axial distance from GMLI

$\Delta_{f} \quad$ Flame-front axial coordinate with respect to GMLI

$|\nabla O H|_{\max } \mathrm{OH}$ LIF signal maximum gradient 
Full-length article submitted to Combustion and Flame

\section{Introduction}

Lean premixed combustion is a straightforward strategy for reducing emissions and increasing efficiency but is difficult to implement in highlyturbulent devices because of instabilities and the increased risk of blowoff [1].Mixture stratification is an effective approach to improve overall-lean combustion stability where lean and weak flames are supported by regions of richer and more robust burning. In some systems, achieving homogeneous mixing is technically not possible and stratification, if not deliberate, is simply unavoidable. The practical relevance of stratified-premixed combustion has motivated an increasing body of work in fundamental combustion research [2]. Effects of mixture stratification are essentially twofold, depending on whether they are associated with either local or largescale inhomogeneity of the reactant stoichiometry [3]. Studies of local reactant inhomogeneity in different laboratory configurations [4-12] have shown that stratification increases the turbulent flame speed as a result of larger turbulent flame density and curvature relative to the corresponding homogeneouslypremixed cases. Additionally, as flame fronts propagate across equivalence ratio gradients, front- and back-support can enhance the burning rates and extend the flammability limits [1318]. These effects, however, seem to prevail at low turbulence intensities [19-20] and become dominated by turbulent transport as the turbulence intensity is increased [11, 21-22] or by flame instabilities for certain types of fuels and mixtures [23].

Under moderately turbulent conditions, Mastorakos [24] introduced a counterflow burner where a stream of reactants was opposed to a second stream of combustion products diluted by air. In previous studies [25-26], by introducing a new turbulence generation scheme [27], we succeeded in raising the turbulent Reynolds number to values on the order of one thousand and examined the interaction of turbulent premixed flames with hot combustion products in the same counterflow configuration. The equivalence ratio of the flame generating the products was maintained at unity while parameters controlling the fluid dynamics, such as the bulk strain rate and the turbulent Reynolds number, and the chemistry, such as the reactant equivalence ratios and the temperature of the product stream, were varied independently.

The present study focuses on large-scale stratification effects pertaining to the interaction of premixed flames with hot combustion products that originate from a flame of different stoichiometry. Figure 1 illustrates such a situation relevant to systems involving large recirculation zones such as swirlstabilized combustors, stratified-premixed gas turbines [28-31] and trapped vortex combustors [32-35]. 
Full-length article submitted to Combustion and Flame

Combustion products from flame fronts of local equivalence ratio $\varphi_{b}$ may be advected towards and interact with flame fronts of a different equivalence ratio, $\varphi_{u}$. In this study, except for some global ignition experiments, the temperature of the products was kept constant while the equivalence ratios of the reactant and product streams were varied independently. Regime diagrams of turbulent premixed combustion [36] provide a conceptual framework to systematize the turbulence-flame interactions but rely on oversimplified assumptions andneglect the effects of mixture stratification.

The role of product stoichiometry is often overlooked relative to the product temperature even in laminar flame studies. The enhancing effect of heat fluxes on heat release and extinction limits has been long recognized [37] and validated [17, 38-40]. In an adiabatic system, stoichiometric combustion products are expected to provide stronger support than either lean or rich flames at lower temperature. With a new focus on the effects of product stoichiometry, the quasi-steady extinction of strained laminar $\mathrm{CH}_{4}$ /air-premixed flames was investigated numerically using detailed chemistry and transport mechanisms in Ref. [41]. For product temperatures exceeding $1600 \mathrm{~K}$, two modes of extinction occurred depending on the product stoichiometry: abrupt extinction, when the products were nearly stoichiometric and smooth extinction when the products came from a lean flame. The presence of oxygen in lean counterflowing combustion products at a mole fraction as low as $10^{-2}$ prevented abrupt extinction. The present study investigates these scenarios under broader conditions, including a rich product stoichiometry and turbulent flow.

Laser diagnostics were employed for simultaneouslaser-induced fluorescence (LIF) imaging of either $\mathrm{CH}_{2} \mathrm{O}$ and $\mathrm{OH}$ or $\mathrm{CO}$ and $\mathrm{OH}$. For appropriate choices of the LIF excitation and detection schemes, the product of the LIF images yields in the first case a quantity proportional to the forward reaction rate of $\mathrm{CH}_{2} \mathrm{O}+\mathrm{OH} \rightarrow \mathrm{HCO}+\mathrm{H}_{2} \mathrm{O}$, and in the second case a quantity proportional to the forward reaction rate of $\mathrm{CO}+\mathrm{OH} \rightarrow \mathrm{CO}_{2}+\mathrm{H}$. The peak reaction rate of the former reaction is correlated with the primary peak of heat release for lean-to-stoichiometric $\mathrm{CH}_{4} /$ air premixed flames [4244]. The latter reaction is a critical step for the conversion of $\mathrm{CO}$ to $\mathrm{CO}_{2}$ that accounts for a third of the heat release as the dominant contribution in the oxidation layer of premixed flames.

The following sections begin with an introduction of the flow conditions, burner and experimental methodologies. The results are divided into three sections. After discussing the global stability and ignition limits of the flames, we examine the flame structure, address the influence of the combustion products and the nature of the flame front topology for different product stoichiometries. 
Full-length article submitted to Combustion and Flame

\section{Experimental methods}

\subsection{Turbulent counterflow burnerand experimental conditions}

The counterflow configuration (Fig. 2a) consisted of a turbulent stream of premixed reactants issuing from the upper nozzle and flowing against a stream of combustion products in thermodynamic equilibrium issuing from the lower nozzle.As depicted in Fig. 2b, turbulent premixed flames ignite and stabilize on top of counterflowing combustion products.The burner design [25-26] allowed for varyingindependently the bulk strain rate, $K_{b u l k}$, the turbulent Reynolds number, $\mathrm{Re}_{\mathrm{t}}$, the temperature of the hot product stream, $T_{b}$, and the equivalence ratios of the reactant and product streams, $\varphi_{u}$ and $\varphi_{b}$, respectively.In thisstudy,reactant and product equivalence ratios were varied usingthe flow conditions given in Table 1.Simultaneous $\mathrm{CH}_{2} \mathrm{O} / \mathrm{OH}$ LIF and simultaneous $\mathrm{CO} / \mathrm{OH}$ LIF measurements were

performed for lean-to-stoichiometric reactants and products.Additional OH LIF measurements were acquired for rich reactants as well as rich products.

The flow rate emerging from the upper nozzle was 85 LPM, resulting in a bulk jet exit velocity of $V_{\text {bulk }}=11.2 \mathrm{~m} / \mathrm{s}$. The bulk strain rate, defined as $K_{\text {bulk }}=2 V_{\text {bulk }} / d_{\text {nozzle }}$ was varied from $1400 / \mathrm{s}$ to $2240 / \mathrm{s}$ by changing the nozzle separation, $d_{\text {nozzle }}$, from $16 \mathrm{~mm}$ to $10 \mathrm{~mm}$. Fully developed turbulence of thereactant streamwas generated by a high-blockage ratio turbulence generator plate housed inside the upper nozzle [45-46].Turbulence properties were determined at the nozzle exit using hot-wire anemometry. The axial velocity fluctuations, $v^{\prime}$, and the integral length scale, l', werev' $=3.9 \mathrm{~m} / \mathrm{s}$ and $l^{\prime}=4.1 \mathrm{~mm}$. The turbulent Reynolds number, defined as $R e_{t}=v^{\prime} l^{\prime} / v$, was 1,050 .

For the $\mathrm{CH}_{4} / \mathrm{O}_{2} / \mathrm{N}_{2}$ reactant mixture, the equivalence ratio, $\varphi_{u}$, was varied from 0.5 to 1.2 and the $\mathrm{O}_{2} / \mathrm{N}_{2}$ molar ratio was 30/70. The adiabatic flame temperature, $T_{a d}$, the laminar flame speed, $S_{L}$, and the laminar flame thickness, $l_{F}$,of the premixed flames were computed using ChemkinPREMIX [47] and the UCSD chemical kinetic mechanism [48] and are listed in Table 2. The laminar flame thickness was defined based on the maximum temperature gradient as $l_{F}=\left(T_{a d}-T_{u}\right) /(\nabla T)_{\max }$ where $T_{u}$ is the unburned gas temperature of $294 \mathrm{~K}$. The Karlovitz number, defined as $K a_{t}=\left(u^{\prime} / S_{L}\right)^{3 / 2}\left(l_{F} / l^{\prime}\right)^{1 / 2}$, was varied by one order of magnitude from 2.7 to 29 . All the premixed flames nominally belonged to the thinreaction zone regime [49-50] (Fig. 3), but with some degree of localized extinction.In the conventional regime diagram of turbulent premixed combustion, no provisions are made for the role of the product stoichiometry, and thus the flames listed in Table 2 have the same coordinates in theregime diagramof Fig. 3 regardless of the equivalence ratio of the product stream. 
Full-length article submitted to Combustion and Flame

The stream of combustion products was produced by a $\mathrm{CH}_{4} / \mathrm{O}_{2} / \mathrm{N}_{2}$ premixed flame that was stabilized on a preburner within the bottom nozzle and operated at an equivalence ratio, $\varphi_{b}$, of either 0.7 , 1.0 or 1.2.Although the resulting hot productstream was quasi-laminar, velocity fluctuations at the bottom nozzle inlet were induced by the upper turbulent jet [26]. To maintain aconstant product stream temperature, $T_{b}$, at $1850 \mathrm{Kand}$ vary the equivalence ratio $\varphi_{b}$, we varied theO $\mathrm{O}_{2} / \mathrm{N}_{2}$ molar ratio of the preburner flamefrom 38/62 for $\varphi_{b}=0.7$, to $26 / 74$ for $\varphi_{b}=1.0$ and 29/71 for $\varphi_{b}=1.2$. The uncertainties in the equivalence ratios and dilution are estimated to be between $1-2 \%$.

\section{$2.2 \mathrm{CO}+\mathrm{OH}$ reaction rate imaging}

Simultaneous imaging of single-photon OH LIF and two-photon CO LIF was used to measure the relative forward reaction rate of the $\mathrm{CO}+\mathrm{OH} \rightarrow \mathrm{CO}_{2}+\mathrm{H}$ reaction. This diagnostic approach enabled us to probe the $\mathrm{CO}$ to $\mathrm{CO}_{2}$ conversion rate in lean-to-stoichiometric $\mathrm{CH}_{4} / \mathrm{O}_{2} / \mathrm{N}_{2}$ flames. A diagram of the experimental system, consisting of two lasers, three cameras, and the axisymmetric counterflow burner, is shown in Fig. 4a. The reaction rate imaging technique was previously described in detail elsewhere [51-53]. The forward reaction-rate, $k_{\mathrm{CO}+\mathrm{OH}}$, is given by $k_{\mathrm{CO}+\mathrm{OH}}=k(T)[\mathrm{CO}][\mathrm{OH}]$, where $k(\mathrm{~T})$ is the temperature-dependent rate constant. The product of the LIF signals from $\mathrm{CO}$ and $\mathrm{OH}$ can be approximated by $k_{\mathrm{CO}+O H}^{L I F}=f_{C O}(T) f_{O H}(T)[C O][O H]$, where the temperature dependence of the LIF signals is represented by $\mathrm{f}_{\mathrm{i}}(\mathrm{T})$. The pump/detection scheme determines the temperature dependence of the LIF signals and can be selected such that $f_{C O}(T) f_{O H}(T) \propto k(T)$. When this relationship is achieved, the pixel-by-pixel product of the OH LIF and CO LIF signals is proportional to the forward reaction rate, i.e. $k_{\mathrm{CO}+\mathrm{OH}}^{\mathrm{LIF}} \propto k_{\mathrm{CO}+\mathrm{OH}}$. The fidelity of the reaction rate imaging scheme is evaluated in Section 2.4.

Laser-induced fluorescence of $\mathrm{OH}$ was excited by the frequency doubled output of a Nd:YAGpumped dye laser tuned to the $Q_{1}(13) \operatorname{line}(\lambda=285.88 \mathrm{~nm})$ of the $A_{2} \Sigma^{+} \leftarrow X_{2} \Pi^{+}\left(v^{\prime}=1, v^{\prime \prime}=0\right)$ band of OH. An intensified CCD camera $(512 \times 512$ pixels $)$ with aUV camera lens $(f . l .=45 \mathrm{~mm}, f / 1.8)$ was used to record the $\mathrm{OH}$ LIF signal with a spatial resolution of approximately $100 \mu \mathrm{m} / \mathrm{px}$. The image intensifier was gated for $500 \mathrm{~ns}$ bracketing the dye laser pulse. The combination of a UG11 color glass filter and a high-transmission bandpass filter $(T>80 \%, \lambda=305-325 \mathrm{~nm})$ transmitted the $\mathrm{OH}$ fluorescence from the $(0,0)$ and $(1,1)$ bands and blocked out-of-band interferences. The OH LIF images were corrected for the mean spatial variations in the laser sheet and the throughput of the imaging system using OHLIF measurements in the downstream of a burner-stabilized flat premixed flame to record the beam profile. 
Full-length article submitted to Combustion and Flame

Shot-to-shot fluctuations of a few percent were negligible for the subsection of the dye-laser beam that was used for LIF imaging.Each OH LIF image was also corrected forvariations in laser energy along the direction of beam propagation resulting from absorption.For this correction, the path length that the laser beam traversed through the flame was determined from the OH LIF signal in each image, and the resulting absorption was calculated at each location along the direction of beam propagation. We verified the absorption correction by checking that the average of the corrected single-shot OH LIF images was symmetric about the burner axis. The extent of the absorption correction varied on a shot-toshot basis depending on the topology of the turbulent flame. The maximum absorption resulted in a decrease in laser energy of $15 \%$ across theprobe volume. The OH LIF signals were not corrected for local variations in quenching rates and the $\mathrm{OH}$ ground-state Boltzmann distribution.

Two-photon CO LIF was excited by pumping overlapped transitions in the $B_{1} \Sigma^{+} \leftarrow \leftarrow X_{1} \Sigma^{+}$ $\left(v^{\prime}=0, v^{\prime}=0\right)$ Hopfield-Birge system of $\mathrm{CO}$ using the frequency-doubled outputs from two separate $10 \mathrm{~Hz} \mathrm{Nd:YAG-pumped} \mathrm{optical} \mathrm{parametric} \mathrm{oscillators} \mathrm{(OPO)}(14 \mathrm{~mJ}$ and $16 \mathrm{~mJ} /$ pulse at $\lambda=230.1 \mathrm{~nm})$, while operating in the sub-quadratic COLIF regime. A cylindrical lens was used to combine the laser beams into a14-mm-highlaser sheet.The CO fluorescence was imaged onto an intensified CCD camera $(512 \times 512$ pixels $)$ using a combination of a medium-format camera lens $(f . l .=80 \mathrm{~mm}, f / 2)$ and a 35-mm format lens $(f . l .=58 \mathrm{~mm}, f / 1.2)$. The imaging system included a dual-band interference filter ( $\Delta \lambda=10 \mathrm{~nm}$ per band) that blocked out-of-band interference and transmitted fluorescence from the $B_{1} \Sigma^{+} \rightarrow A_{1} \Pi\left(v^{\prime}=0, v^{\prime}=1,2\right)$ transitions of $\mathrm{CO}$ at $\lambda=483.5 \mathrm{~nm}$ and $519.8 \mathrm{~nm}$. For the lean and stoichiometric flames considered here, the dual-band filter provided greater signal collection than a single-band filter with negligible interference from laser-generated $\mathrm{C}_{2}$ Swan band emission. The spatial resolution was approximately $100 \mu \mathrm{m} / \mathrm{px}$. The image intensifier was gated for $500 \mathrm{~ns}$, bracketing the OPO laser pulses. Shot-to-shot variations in the beam profile were recorded by splitting off portions of the 230-nm beams after the cylindrical lens and focusing them into a cell with quartz windows containing $\mathrm{CO}$ and $\mathrm{N}_{2}$ at atmospheric pressure and ambient temperature. The CO LIF signal from the cell was recorded on an un-intensified CCD camera, and the resulting images were used to correct the CO LIF measurements in the counterflow flames for beam profile variations and signal intensity variations associated with the non-uniformity of the beam thickness across the probe volume. Additional uncorrected variations in the beam profile arise from beam steering as a result of the laser beam traversing the index of refraction gradients in the turbulent flames. 
Full-length article submitted to Combustion and Flame

The two-dimensional reaction rate measurements required subpixel matching of the camera imaging planes for $\mathrm{OH}$ LIF and CO LIF, which was achieved using fine dotted targets and a bilinear warpingalgorithm for image registration. To insure that the OH LIF and CO LIF measurement planes were coincident, we carefully overlapped the two laser beams over distances that were significantly larger thanthe field of view for LIF imaging.

\section{$2.3 \mathrm{CH}_{2} \mathrm{O}+\mathrm{OH}$ reaction rate imaging}

The relative forward reaction rate of the $\mathrm{CH}_{2} \mathrm{O}+\mathrm{OH} \rightarrow \mathrm{HCO}+\mathrm{H}_{2} \mathrm{O}$ reaction, $k_{C H 2 O+O H}$, was measured using simultaneous $\mathrm{OH}$ LIF and $\mathrm{CH}_{2} \mathrm{O}$ LIF imaging in the same series of lean-tostoichiometric $\mathrm{CH}_{4} / \mathrm{O}_{2} / \mathrm{N}_{2}$ flames as the $\mathrm{CO} / \mathrm{OH}$ LIF measurements. A diagram of the experimental system is shown in Fig. 4b. Similarly to the $\mathrm{CO}+\mathrm{OH}$ reaction rate imaging, the LIF pump/detection scheme for measurement of $k_{\mathrm{CH} 2 \mathrm{O}+\mathrm{OH}}$ was selected such that the pixel-by-pixel product of the OH LIF and $\mathrm{CH}_{2} \mathrm{O}$ LIF images yields a quantity proportional to $k_{\mathrm{CH} 2 \mathrm{O}+\mathrm{OH}}$, i.e. $k_{\mathrm{CH} 2 \mathrm{O}+\mathrm{OH}}^{\mathrm{LIF}} \propto$ $k_{\mathrm{CH} 2 \mathrm{O}+\mathrm{OH}}$. Simultaneous imaging of $\mathrm{CH}_{2} \mathrm{O}$ LIF and $\mathrm{OH}$ LIF has previously been used to probe the primary peak of heat release rate in laminar [42-44] andturbulent premixed flames [54-58].

The OH LIF excitation and detection system was similar to that used for the $\mathrm{CO} / \mathrm{OH} \mathrm{LIF}$ measurements. The same laser system was tuned to the $Q_{1}(6)$ line $(\lambda=283.01 \mathrm{~nm})$ of the $A_{2} \Sigma^{+} \leftarrow X_{2} \Pi^{+}$ $\left(v^{\prime}=1, v^{\prime}=0\right)$ band of $\mathrm{OH}$. The use of a different $\mathrm{OH}$ rotational level improved the proportionality between the product of the $\mathrm{CH}_{2} \mathrm{O}$ and $\mathrm{OH}$ LIF signals and the corresponding reaction rate. The OH LIF measurements were corrected in the same manner as described Section 2.2.

Laser-induced fluorescence of formaldehyde was excited by the third harmonic of an injection seeded Nd:YAG laser. The diode seed laser was temperature tuned to $\lambda=354.83 \mathrm{~nm}$ to excite overlapping transitions in the $4_{0}^{1}$ band of the $\tilde{A}^{1} A_{2} \leftarrow \tilde{X}^{1} A_{1}$ system. The $355 \mathrm{~nm}$ laser beam was formed into a sheet that overlapped the $283 \mathrm{~nm}$ beam within the probe volume. The $\mathrm{CH}_{2} \mathrm{O}$ fluorescence emission was imaged onto an intensified CCD camera using a medium-format camera lens, an ARcoated singlet (f.l. $=-400 \mathrm{~mm}$ ), and a $35-\mathrm{mm}$ format lens. A color glass filter (GG375) in the imaging system blocked elastic scattering from the laser and transmitted the $\mathrm{CH}_{2} \mathrm{O}$ LIF signal. In addition, the laser beam was horizontally polarized to eliminate interferences from Rayleigh or Raman scattering.

Passive, single-cavity pulse stretchers were employed in the $\mathrm{CH}_{2} \mathrm{O}$ and $\mathrm{OH}$ LIF systems to approximately double the effective duration of the UV laser pulses. The longer laser pulses enabled the 
Full-length article submitted to Combustion and Flame

use of greater laser energy, viz. $1.2 \mathrm{~mJ} /$ pulse for $\mathrm{OH}$ LIF and $42 \mathrm{~mJ} /$ pulse for $\mathrm{CH}_{2} \mathrm{O}$ LIF, while operating in the linear LIF regime.

\subsection{Fidelity of the LIF and reaction rate measurements}

In the analysis of the turbulent counterflow flames, we use the $\mathrm{OH} / \mathrm{CO} / \mathrm{CH}_{2} \mathrm{O}$ LIF signals directly as well as the pixel-by-pixel product of LIF signals to determine quantities proportional to reaction rates. Conversion of the LIF signals into species mole fraction would have requiredadditional simultaneous measurements of temperature and other major species. The discrepancies betweenprofiles of scaled LIF signals and species mole fractionswere estimated using temperature and species data from laminar flame calculations to simulate LIF signal profiles across a laminar counterflow flame. The simulations of LIF signals werelimited by the availability of detailed data on energy transfer processes, such as collisional quenching, rotational energy transfer (RET), and vibrational energy transfer (VET).The LIF simulations included calculations of variations in theBoltzmann distributions and LIF quenching rates for the excited transitions.Quenching rates for OH LIF and CO LIF were computed using the quenching cross sections from Tamura et al. [59] and Settersten et al. [60], respectively.For CO LIF, the ionization rate wasestimated using the ionization cross section from Di Rosa and Farrow[61]. For simulation of $\mathrm{CH}_{2} \mathrm{O}$ LIF signals, the temperature dependence of the Boltzmann distribution of the lower states of the $4_{0}^{1}$ band of the $\tilde{A}^{1} A_{2} \leftarrow \tilde{X}^{1} A_{1}$ system was calculated using Asyrot spectral simulation software [62]. The availability of relevant data on the temperature dependent quenching rates for $\mathrm{CH}_{2} \mathrm{O}$ LIF is very limited. As a result, the temperature dependence was modeled using an assumed $T^{0.5}$ dependence, as in previous work [63].Although this assumptioninvolvesuncertainty,its use does not appreciably alter the conclusionsofour study. Alternative possibilities for temperature dependence models changed the proportionality constant between the reaction rate and the product of the LIF signals, but the two quantities maintained the proportionality relationship over the relevant temperature range.

Computed profiles of $\mathrm{OH}, \mathrm{CO}$ and $\mathrm{CH}_{2} \mathrm{O}$ mole fractions for a lean, freely propagating laminar premixed flame $\left(\varphi_{u}=0.7\right)$ are plotted in Fig. 5a.The mole fraction profiles are normalized by their respective peak values and compared to the corresponding peak-normalized simulated LIF signalsin Fig. 5b. The abscissa, $x_{n}$, is centered at the location of the maximum gradient of $\mathrm{OH}$ mole fraction in Fig. 5a and of the computed OH LIF signal inFig. 5b.Overall,the normalized profiles of the LIF signals are in good agreement with the corresponding mole fraction profiles. The main discrepancies are: the positions of the peak $\mathrm{CO}$ and $\mathrm{CH}_{2} \mathrm{O}$ LIF signals areslightly shifted upstream toward lower temperatures 
Full-length article submitted to Combustion and Flame

relative to the corresponding peak mole fractions; the CO LIF profile is broader than theCO mole fraction profile; and, toward the flame products, the OH LIF signal decays slightly faster than $\mathrm{OH}$ mole fraction.If a different temperature dependence is used for modeling the $\mathrm{CH}_{2} \mathrm{O}$ LIF collisional quenching, the peak of the simulated $\mathrm{CH}_{2} \mathrm{O}$ LIF signal shifts slightly.

This laminar flame calculation was also used to evaluate the fidelity of therelative reaction rate profile measurements for the LIF excitation and detection schemes describedin Sections 2.2 and 2.3. The forward reaction rates, $k_{\mathrm{CH} 2 \mathrm{O}+\mathrm{OH}}$ and $k_{\mathrm{CO}+\mathrm{OH}}$, are plotted in Fig. 5a,and the quantities resulting from the products of the simulated LIF signals, $k_{\mathrm{CH} 2 \mathrm{O}+\mathrm{OH}}^{\mathrm{LIF}}$ and $k_{\mathrm{CO}+O H}^{\mathrm{LIF}}$, are plotted in Fig. 5b.Over the temperature range of significant $\mathrm{CO}+\mathrm{OH}$ reaction $(1600-2400 \mathrm{~K})$, the correspondence between the $\mathrm{K}_{\mathrm{CO}+O \mathrm{H}^{2}}$ and $k_{\mathrm{CO}+\mathrm{OH}}$ profiles is excellent. Similar agreement was observed for the other lean-to-stoichiometric flames considered here with an estimated deviation on the order of $\pm 5 \%$, which is within the uncertainty of the estimate. The profile of $\mathrm{CH}_{\mathrm{CH}+\mathrm{OH}}^{\mathrm{LIF}}$ is also in good agreement with the $\mathrm{CH}_{2} \mathrm{O}+\mathrm{OH}$ reaction rate, despite a small amount of broadening and a shift of the peak location towards the reactants.In the remainder of the article, the measured reaction rates for $\mathrm{CO}+\mathrm{OH}$ and $\mathrm{CH}_{2} \mathrm{O}+\mathrm{OH}$ will be directly denoted $\mathrm{K}_{\mathrm{CO}+\mathrm{OH}}$ and $k_{\mathrm{CH} 2 \mathrm{O}+\mathrm{OH}}$, respectively.

\section{Results and discussion}

\subsection{Extinction/Ignition of Strained Laminar Premixed Flames}

To help understand the effects of counterflowing products on turbulent flames, we firstuse strained laminar premixed flame calculations [47-48] to analyze the extinction and ignition of laminar flames with different product and reactant streamequivalence ratios. These calculations include counterflowing streams of premixed reactants with equivalence ratios $\varphi_{u}$ equal to $0.7,1.0$ and 1.2 and combustion products with equivalence ratios $\varphi_{b}$ equal to $0.7,1.0$ and 1.2 in thermochemical equilibrium at a temperature of $T_{b}=1850 \mathrm{~K}$. The $\mathrm{O}_{2} / \mathrm{N}_{2}$ molar ratios were prescribed as discussed in Section 2.1. In Fig. 6, we compare the variations of peak mole fractions of $\mathrm{OH}, \mathrm{CO}$ and $\mathrm{CH}_{2} \mathrm{O}$ with those of peak heat release rates in the lean, rich and stoichiometric premixed flames as a function of the strain rate for $\varphi_{b}=0.7$. The strain rate is defined as $S R=2 V_{\text {reactant }} / d_{\text {nozzle }}$, where $V_{\text {reactant }}$ is the imposed velocity at the cold inlet. The ordinates are normalized by the corresponding peak values in an unstrained laminar premixed flame at the same equivalence ratios. As the strain rate increases, the peak heat release rates of all three premixed flames decrease monotonically. Peak mole fractions of $\mathrm{OH}, \mathrm{CO}$ and $\mathrm{CH}_{2} \mathrm{O}$ generally follow the same trend, but with a more gradual decaythan the peak heat release rate, except for a small 
Full-length article submitted to Combustion and Flame

overshoot of the $\mathrm{OH}$ mole fraction in the rich premixed flame. For the three premixed flames, $\mathrm{CH}_{2} \mathrm{O}$ is the slowest of the three species to be depleted as the strain rate increases.

In Fig. 7, normalized peak heat release rates of the lean, rich and stoichiometric premixed flames are plotted as a function of their distance, $\Delta_{f}$, from the gas stagnation plane where the axial velocity is zero. As the strain rate increases, the flame front is invariably displaced closer to the gas stagnation plane [41]. For $\Delta_{f}$ greater than $1.75 \mathrm{~mm}$, peak heat release rates decrease very modestly for decreasing $\Delta_{f}$ and are relatively insensitive tovariations in strain rate and product stoichiometry. The "zone of influence" of the counterflowing products can be identified for $\Delta_{f}$ less than approximately $1.75 \mathrm{~mm}$ wherepeak heat release rates are affected by mixing of the reaction zone with the counterflowing combustion products and the flames approach extinction differently depending on the product stream stoichiometry. For strain rates as low as 500/s, the premixed flames are displaced into the region of $\Delta_{f}<1.75 \mathrm{~mm}$ and, therefore, are easily affected by the counterflowing stream of combustion products.

Two modes of extinction are identified depending on the composition of the product stream: 1 ) abrupt extinction, corresponding to a sudden drop of peak heat release rate following an incremental increase in strain rate, and 2) smooth extinction, where the heat release rate decays monotonically as the strain rate is increased,asshown in Fig. 6. For stoichiometric and rich counterflowing combustion products, the premixed flames extinguish abruptly with extinction strain rates displayed in Fig. 8.Rich products make the flame more robust with larger extinction strain rates than the flames with stoichiometric products. This enhancement is most pronounced for the lean reactant mixture $\left(\varphi_{u}=0.7\right)$ in which large amounts of $C O$ from the rich product stream are readily consumed by excess $\mathrm{O}_{2}$ in the lean reactants. The maximum strain rates at which the reactant mixture will ignite by mixing with the product stream are also shown in Fig. 8. The maximum ignition strain rates are higher for therich products than for the stoichiometricproducts, indicating that ignition is hindered by stoichiometric products.In the presence of lean counterflowing products $\left(\varphi_{b}=0.7\right)$, extinction and re-ignitionoccur in a smooth transition with the peak heat release rate varying monotonically as a function of the strain rate, as shown inFig. 6. In this case, we define the extinction/ignition point as the condition where the peak heat release rate is $10 \%$ of its value in the corresponding unstrained laminar flame. Figure 8 shows that the extinction and ignition strain rates for the lean product stream are on the order of 3500/s, regardless of the reactant equivalence ratio, indicating that the back-support providedby the lean product stream is quite significant. As discussed in [41], abrupt extinction of the premixed flames result from the rapid depletion of the radical pool composed of $\mathrm{H}, \mathrm{OH}$ and $\mathrm{O}$. In the presence of lean products, smooth 
Full-length article submitted to Combustion and Flame

extinction is permitted by the slower decay of the $\mathrm{OH}$ radical concentration. Previous numerical simulations have shown that the transition of the extinction/ignition mode from abrupt to smooth occurs for a small departure of the product equivalence ratio from stoichiometric to lean [41].

These results conclusively show that the premixed flame burning rate and extinction/ignition cannot be solely characterized in terms of strain rate. The displacement of the flame front in the vicinity of the gas stagnation plane combined with the temperature and composition of the counterflowing stream play critical roles in determining the mode of extinction and ignition, i.e. abrupt or smooth, and the onset of extinction/ignition. These results from laminar flame calculations provide a framework for investigating the effects of stratification in turbulent premixed flames.

\subsection{Conditions of turbulent flame global ignitionand stability}

Before we examine in detail the structure of turbulent premixed flames, we first addressthe important role of the stoichiometry globally by considering the ignitability of turbulent premixed reactants. In Ref. [26], ignitability of reactants by stoichiometric combustion products and combustion stability were shown to increase at higher product temperatures and lower bulk strain rates. Extending these results, we consider the influence of the product stoichiometry on global ignition and stability of turbulent premixed flames. In Fig. 9, the measured ignition and stability limits of lean $\left(\varphi_{u}=0.7\right)$, stoichiometric $\left(\varphi_{u}=1.0\right)$ and rich $\left(\varphi_{u}=1.2\right)$ premixed reactants are shown for counterflowing product stream temperatures, $T_{b}$, from $1500 \mathrm{~K}$ to $2000 \mathrm{~K}$, and equivalence ratios, $\varphi_{b}$, from 0.7 to 1.2 .For each combination of $T_{b}, \varphi_{b}$ and $K_{b u l k}$, we determined whether or not premixed reactants with equivalence ratio $\varphi_{u}$ ignited solely by mixing with the stream of combustion products and without the support of an external ignition source.Ignition is possible for product temperatures, $T_{b}$, above the dashed/solid limiting curves. Following ignition, combustion is either pulsing (domain between dashed lines and solid lines) or stable (domain above solid lines). In the pulsing regime, combustion switches on and off spontaneously and repeatedly at frequencies between approximately $1 \mathrm{~Hz}$ and $10 \mathrm{~Hz}$. This unstable regime is characterized by strong acoustic pulses as the flame brush sequentially extinguishes and reignites.In the stable regime, however, the flame brush burns steadily without intermittent blow-off.

The rationale for global flame ignition and stability is defined by the competition between the ignitability of the reactants by the counterflowing products and the ability of the turbulent flame to sustain itself [26]. As the product temperature increases, reactant ignitability increases and the global stability of the flame improves. In Fig. 9a,the global ignition and stability of lean, rich, and 
stoichiometric premixed flames are compared for $K_{b u l k}=1400 /$ s.For the three turbulent flames, ignition and stability are most facilitated by lean combustion products and most limited in the presence of stoichiometric products. For $\varphi_{b}=0.7$, the stoichiometric flame is the most stable of the three flames.As $\varphi_{b}$ is increased to unity, ignition of the rich turbulent flame is hampered the most. For $\varphi_{b}>1.0$, ignition of the rich flame requires higher product temperatures than the lean and stoichiometric premixed flames. Unlike the stoichiometric flame, the lean and rich flames operate in the pulsing regime at reduced temperatures. These turbulent flames interact more with the product stream than the stoichiometric flame. Their stability, therefore, depends on the product stream temperature and composition to a greater extent. These global flame behaviors generally follow the extinction/ignition trends observed for laminar flame calculations in Section 3.1.

In Ref. [26], for $K_{b u l k}=1400 / \mathrm{s}$, the stoichiometric premixed flame was shown to be virtually unaffected by the temperature of the stoichiometric productstream because the flame brush was located sufficiently far from the combustion products. When $K_{\text {bulk }}$ is raised to 2240/s (Fig. 9b), ignition of a stable stoichiometric premixed flame requires noticeably higher product temperatures or leaner/richer counterflowing products. Combustion remains most limited in the presence of a stoichiometric productstream. The global stability of the stoichiometric premixed flame becomes strongly dependent on $T_{b}$ and $\varphi_{b}$.The pulsing combustion limit, which does not exist for the lower strain rate case, lies approximately $100 \mathrm{~K}$ below the stable regime limit.For $T_{b}-\varphi_{b}$ conditions that are below the pulsing regime limit, ignition of the stoichiometric premixed reactants by the counterflowing products is no longer possible and the flame cannot be ignited, not even by using an external ignition source.

These experiments provide qualitative evidence that product stream stoichiometry affects the survivability ofturbulent premixed flames. One would expect that detailed measurements of the flame structure should confirm this finding.

\subsection{Turbulent premixed flame structure}

The influence of counterflowing products onturbulent premixed flame structure and reaction rates were investigated using two independent series of $\mathrm{CH}_{2} \mathrm{O} / \mathrm{OH}$ LIF and $\mathrm{CO} / \mathrm{OH}$ LIFmeasurements. For these measurements, only the equivalence ratios of the reactant and product streams were varied and the other experimental parameters were fixed, with $K_{b u l k}=1400 / \mathrm{s}, R e_{t}=1050$ and $T_{b}=1850 \mathrm{~K}$ (Table 1 ). Under these conditions, the turbulent flames were globally stable (Fig. 9). 
Full-length article submitted to Combustion and Flame

As shown by the laminar flame calculations in Section 3.1,monitoring the distance separating the flame fronts from the product stream is of paramount importance. To that end, we define the equivalent of the gas stagnation plane under turbulent conditions asthe Gas Mixing Layer Interface (GMLI),separating the turbulent opposed streams. The new definition is required since the GMLI is not fixed in space and time, unlike the gas stagnation plane, but fluctuates as a result of turbulence. The GMLI was identified using the OH LIF imagesin each ofthe two series of LIF measurements using the technique developed in previous work [26] and described here for completeness. The GMLIwas determined in each single-shot OH LIF image using the procedure illustrated in Fig. 10. In this OH LIF snapshot,cold reactants and turbulent flames are located on top of the GMLI, and the counterflowing products occupy the space below.Regions occupied by reactants,turbulent flames and products are readily identified. In the cold premixed reactants, the OH LIF signal is near zero. The combustion products issuing from the bottom nozzle contain small amounts of $\mathrm{OH}$ radicals and, since the counterflowing products are in thermodynamic equilibrium, the concentration of $\mathrm{OH}$ radicals present in the product stream is fairly homogeneous. As a result, the OH LIF signal in the product stream is relatively low and uniform. In theturbulentpremixed flames, the OH LIF signal is significantly higher than in the product stream.

Thelocation of the GMLI contourwas determined from themagnitude of thegradient of the OH LIF signal.For each column of pixels in the OH LIF image, the GMLIposition was identified as the first peak in the magnitude of the gradient of the OH LIF signal starting from the bottom of the image. Any subsequent peaks in the $\mathrm{OH}$ LIFsignal gradient corresponded toflame fronts.This procedure is demonstrated in the three plots in Fig. 10 where profiles of the $\mathrm{OH}$ LIFsignal and the magnitude of its gradient are plotted along each of the three pixel columns labelled (1), (2) and (3) in the OH LIF snapshot. The GMLI and the flame front positions are successfully identified in column (1) where the premixed flame is attached to the GMLI,in column (2)where the small region of partiallyextinguished premixed flameis attached to the GMLI and in column (3)where thepremixed flame is detached from the GMLI and the product stream transitions directly into the reactants.Because of the convoluted flame morphology, there can be more than one flame front per pixel column, e.g. columns (2) and (3).The distance that separates the turbulent flame fronts from the GMLI is denoted as $\Delta_{f}$, following the notation for the laminar flame calculations in Section 3.1

Examples of simultaneous $\mathrm{CH}_{2} \mathrm{O} / \mathrm{OH}$ LIF and simultaneous $\mathrm{CO} / \mathrm{OH}$ LIF measurementsare displayed in Figs. 11a and 11b, respectively, for a lean $\left(\varphi_{u}=0.7\right)$ turbulent premixed flameopposed to 
Full-length article submitted to Combustion and Flame

either lean $\left(\varphi_{b}=0.7\right)$ or stoichiometric $\left(\varphi_{b}=1.0\right)$ combustion products. The premixed flames stabilize on top of the counterflowing combustion products and away from the nozzles, which are located at $Z= \pm 8 \mathrm{~mm}$. Contours of the GMLI were determined by applying the procedure described above to each of the single-shot OH LIF images. The GMLI is unsteady and moderately corrugated as a result of the interaction between the turbulent reactant stream and the nearly laminar product stream and is typically located between $z=-4 \mathrm{~mm}$ and $z=2 \mathrm{~mm}$ [26].In laminar premixed flames, the concentration of $\mathrm{OH}$ rises sharply in the fuel consumption layer and decays more gradually in the oxidation layer.In turbulent flames, the flame front leading edge corresponds to the boundary of the OH LIF layer. The gradual decay of $\mathrm{OH}$ in the flame is not systematically observed because of the unsteady nature of the flow. The regions of high $\mathrm{CH}_{2} \mathrm{OLIF}$ and $\mathrm{CO}$ LIF signalsform layers aligned with the flame front contours. The thickness of these layers and the magnitude of the $\mathrm{CH}_{2} \mathrm{O}$ and $\mathrm{CO}$ LIF signalsare not uniform along the leading edge of the flame. The forward reaction rates are also very non-uniform along the flame front contour. Regions of high $\mathrm{CO}$ LIF and $\mathrm{CH}_{2} \mathrm{O}$ LIF signals do not necessarily result in large reaction rates due to a lack of overlap with the OH LIF structures.A lower CO LIF signal is also detected in the products of the turbulent flames where the OH LIF signal is high, resulting in a low rate of oxidation of $\mathrm{CO}$ by $\mathrm{OH}$ in these regions (Fig. 11b).

To evaluate the turbulent flame front structure in more detail, we analyze one-dimensional profiles of the $\mathrm{OH}, \mathrm{CH}_{2} \mathrm{O}, \mathrm{CO}$ LIF signals, as well as the values of $k_{\mathrm{CH} 2 \mathrm{O}+\mathrm{OH}}$ and $k_{\mathrm{CO}+\mathrm{OH}}$ that are sampled along the lines labeled (1), (2) and(3) for the case of $\varphi_{b}=0.7$ in Figs. 11a and 11b. These 2.5 mm-long lines are centered on the leading edges of the flamesat the location of the maximum magnitude of the OH LIF signal gradient, denoted as $|\nabla O H|_{\max }$, and oriented normal to the flame surface. The data along each line are interpolated between pixels, and the results are plotted in Fig. 12. The reaction rates and the LIF signals were normalized with respect to their respective ensemble-averaged values computed for $\Delta_{f} \geq 1.75 \mathrm{~mm}$. The abscissa of each plot, $x_{n}$, is centered at the flame leading edge and is negative toward reactants and positive toward flame products. Although Figs. 11a and 11b were obtained fromseparatesingle-shot measurements, the location of each of the three lines was chosen to sample similar structures within each image.Along line(1), the turbulent flame structure is comparable to that of a laminar premixed flame with high reaction rates.For line(2), the peaks of $\mathrm{CH}_{2} \mathrm{O}$ and $\mathrm{CO}$ are located further upstream of the $\mathrm{OH}$ layer than in the profiles along line (1).As a result, the peak reaction rates along line (2)are approximately 50\% lower than those along line (1), even though the peaks of the $\mathrm{CH}_{2} \mathrm{O}$ LIF and CO LIF signals along line (2) are comparable to those along line (1). The reduced reaction rates 
Full-length article submitted to Combustion and Flame

in regions near line (2)are the result of misalignments of the $\mathrm{CH}_{2} \mathrm{O}$ and $\mathrm{CO}$ layers with the flame leading edge. These species misalignments originate from unsteady turbulence-flame interactions and result in partial quenching of the peak heat release rate and the $\mathrm{CO}+\mathrm{OH}$ reaction. These effects would not be predicted bya flamelet model based on strained laminar premixed flames such as those presented in Section 3.1 [64-65]. These observations arealso affected by thethree-dimensional orientation of the flame front with respect to the imaging plane, resulting in seemingly thicker flame structuresat locations where the flame-normalvector is not parallel to the imaging plane.

The red arrows in the images of Figs. 11a and $11 \mathrm{~b}$ indicate regions where the amount of $\mathrm{OH}$ radicals is substantially reduced near the GMLI.For the stoichiometric product stream $\left(\varphi_{b}=1.0\right), \mathrm{OH}$ radicals can be entirely depleted above of the GMLI. In these regions,even though some amounts of $\mathrm{CH}_{2} \mathrm{O}$ and $\mathrm{CO}$ remain, the $\mathrm{CO}+\mathrm{OH}$ and $\mathrm{CH}_{2} \mathrm{O}+\mathrm{OH}$ reactionsare quenched as a consequence of the absence of $\mathrm{OH}$. For a lean product stream $\left(\varphi_{b}=0.7\right)$, however, a thin layer of low OH LIF signal remains present along the GMLI.In Fig. 12, the flame-normal profiles sampled along line(3)in Fig. 11 show thatthe measured species and reaction rates are diminished in these regions along the GMLI where the flame is partially extinguished.We deduce that the primary heat release rate and the oxidation of $\mathrm{CO}$ by $\mathrm{OH}$ are significantly reduced.Thesedifferences in flame extinction in Fig. 11 can be explained with the results ofthe laminar flame calculations presented in Section 3.1: flames exposed to stoichiometric products are expected to extinguish abruptly whereas the reaction rates in flames exposed to the lean products $\left(\varphi_{b}=0.7\right)$ are expected to decay smoothly with increasing strain rate. The effects of the product stream on localized extinction will be further treated in Section 3.4.

To generalize the observations made on the particular cases examined in Fig. 11, we analyze statistics of theturbulent flame structure computed using thousands of flame-front samples froma minimum of 800 single-shot images. Figure 13a shows the mean flame-normal profiles of $\mathrm{OH}, \mathrm{CO}$ and $\mathrm{CH}_{2} \mathrm{OLIF}$ signals and associated reaction rates. Each profile was normalized by its peak value. The two mean $\mathrm{OH}$ LIF profiles are from the separate data setsthat were acquired in combination with theCH $\mathrm{H}_{2} \mathrm{O}$ and CO LIF measurements. The close agreement between these OH LIF profiles indicates that the two sets of LIF measurements are statistically consistent and can be compared.The mean turbulent flame structure is similar to that ofthefreely propagating laminar premixed flamecomputed for an equivalence ratio of 0.7 that was presented in Fig. 5. The main difference is that all mean profiles extend over a much broader spatial domain as a result of turbulent transport and flame-front folding. The mean reaction rate profiles in Fig. 13a show thatthe peak reaction rate of $\mathrm{CH}_{2} \mathrm{O}$ and $\mathrm{OHis}$ located closer to the reactants 
Full-length article submitted to Combustion and Flame

than the $\mathrm{CO}+\mathrm{OH}$ reaction, which is the primary step intervening in the relatively slow $\mathrm{CO}$ oxidation. This result from the turbulent flame is consistent with the computed laminar flame profiles in Fig. 5, except that the $\mathrm{CH}_{2} \mathrm{O}+\mathrm{OH}$ reaction in the turbulent flame persists significantly farther into the product region.

The effects of turbulence on the premixed flame structureare further analyzed in terms of the peak values of the flame-normal profiles of $\mathrm{CO} \mathrm{LIF}, \mathrm{CH}_{2} \mathrm{O} \mathrm{LIF}$ and the $\mathrm{CO}+\mathrm{OH}$ andCH $\mathrm{H}_{2} \mathrm{O}+\mathrm{OH}$ reaction rates, denoted as $\mathrm{CO}_{\max }, \mathrm{CH}_{2} \mathrm{O}_{\max }, \mathrm{k}_{\mathrm{CO}+\mathrm{OH}}^{\max }$ and $k_{\mathrm{CH} 2 \mathrm{O}+\mathrm{OH}}^{\max }$, respectively. Probability density functions (PDFs) of the positions ofthese peaksalong the flame-normal coordinate are plotted in Fig. 13b. In analyzing Fig. 13b, one must keep in mind the small shifts of the peak CO LIF and $\mathrm{CH}_{2} \mathrm{O}$ LIF signals toward lower temperatures relative to the peak $\mathrm{CO}$ and $\mathrm{CH}_{2} \mathrm{O}$ mole fractions (Fig. 5). The PDF for $\mathrm{CH}_{2} \mathrm{O}_{\text {max }}$ indicates that most of the $\mathrm{CH}_{2} \mathrm{O}$ peaks are located within0.5 mm upstream of maximum $\mathrm{OH}$ gradients.In contrast, the $\mathrm{CO}$ peak positions spread out more broadly and span approximately $0.5 \mathrm{~mm}$ on either side of the maximum $\mathrm{OH}$ gradient.In rare occurrences, $\mathrm{CO}_{\max }$ and $\mathrm{CH}_{2} \mathrm{O}_{\max }$ can be located as far as $x_{n}=-0.8 \mathrm{~mm}$. The peak $\mathrm{CH}_{2} \mathrm{O}+\mathrm{OH}$ reaction ratesare located in an approximately $0.5 \mathrm{~mm}$ band on the reactant side of the peak $\mathrm{OH}$ gradients, whereas the peak $\mathrm{CO}+\mathrm{OH}$ reaction rates areslightly more spread out on the product side of the maximum $\mathrm{OH}$ gradient. The most probable position of these peaks closely coincides with the corresponding peaks in the laminar flame (Fig. 5). However, the spreading of the PDF of $k_{C O+O H}^{\max }$ relative to that of $k_{C H 2 O+O H}^{\max }$ in Fig. $13 \mathrm{~b}$ indicates that the turbulent fluctuations perturb the slow $\mathrm{CO}$ oxidation more than the faster reaction rates occurring in the fuel consumption layer and associated with primary heat release.Biases associated with out-of-plane flame orientation effects would not account for these differences. Overall, the turbulent reaction zones are structurallysimilar to laminar flames but thickened as a result of the turbulent transport, which can result in large fluctuations of the reaction rates as analyzed in the following section.

\subsection{Zone of influence of the product stream on turbulent flame reaction rates}

This section aims at evaluating the zone of influence of the counterflowing product stream on turbulent premixed flamesby establishing relationships between the turbulent flame structure and the distance between the flame fronts and the GMLI by analogy with the discussion presented in connection with Fig. 7 on the basis of laminar flame calculations. Figures 14a and 14b show scatter plots of the maximum $\mathrm{CH}_{2} \mathrm{O}+\mathrm{OH}$ and $\mathrm{CO}+\mathrm{OH}$ reaction rates, $k_{\mathrm{CH} 2 \mathrm{O}+\mathrm{OH}}^{\max }$ and $k_{\mathrm{CO}+O H}^{\max }$, respectively, as a function of the flame front distance from the GMLI, $\Delta_{f}$, for the lean $\left(\varphi_{u}=0.7\right)$ turbulent premixed flame opposed 
Full-length article submitted to Combustion and Flame

to a stream of lean $\left(\varphi_{b}=0.7\right)$ combustion products. The reaction rates and the LIF signals are normalized by their respective ensemble averages computedfor flame fronts that are well separated from the combustion products $\left(\Delta_{f} \geq 1.75 \mathrm{~mm}\right)$. Turbulence-flame interactions cause large variations of the forward reaction rates. However, $\mathrm{k}_{\mathrm{CH} 2 \mathrm{O}+\mathrm{OH}_{\mathrm{H}}}^{\max }$ and $\mathrm{K}_{\mathrm{CO}+\mathrm{OH}}^{\max }$ are preferentially lower in the vicinity of the GMLI, as indicated by the decay in the conditional mean curves shown in each plot. Two regions of the flow can be differentiated depending on the flame front distance from the GMLI.For $\Delta_{f}$ greater than approximately $1.75 \mathrm{~mm}$, the conditional averages of $\mathrm{k}_{\mathrm{CO}+\mathrm{OH}}^{\max }$ and $k_{\mathrm{CH} 2 \mathrm{O}+\mathrm{OH}}^{\max }$ are relatively constant as a function of $\Delta_{f}$. However, for $\Delta_{f}<1.75 \mathrm{~mm}$, the conditional averages decrease rapidly as the flame fronts approach the GMLI. As in the laminar premixed flames (Fig. 7), the counterflowing products affect burning rates of turbulent flame fronts within approximately $1.75 \mathrm{~mm}$ of the GMLI. Turbulent transport has seemingly no effect on the extent of the zone of influence of the product stream. In Ref. [25], strained laminar flame calculations demonstrated that this zone varies more significantly as a function of the thickness of the flame oxidation layer.

The peak locations of the $\mathrm{CO}$ LIF and $\mathrm{CH}_{2} \mathrm{O}$ LIF flame-normal profiles were also monitored as a function of $\Delta_{f}$ for the same lean flame condition $\left(\varphi_{u}=\varphi_{b}=0.7\right)$.However, the flame-normal OH LIF profiles did not always have a clearly defined peak because, in some instances, the OH LIF profiles monotonically increasedor reached a plateau instead of a well-defined maximum,as shown in Fig. 12. Instead of using the OH LIF signal maximum, we analyzed the OH LIF signalat $x_{n}=0$, denoted $O H_{o}$, which corresponds to the location of themaximum OH LIF gradient magnitude, as a function of the distance of the flame fronts from the GMLI.In Figs. 14a and 14b,the conditional averages of $O H_{O}$ decrease significantly near the GMLI. Both sets of OH LIF measurements show this decay, although there is an approximately $20 \%$ discrepancy in the conditional mean values of $\mathrm{OH}_{o}$ near the GMLI as a result of incomplete statistical convergence.In contrast to thissubstantial decay of $\mathrm{OH}_{o}$, the conditional average of $\mathrm{CO}_{\text {max }}$ remains nearly constant and $\mathrm{CH}_{2} \mathrm{O}_{\max }$ decays only slightly near the GMLI. As a result, the depletion of $\mathrm{OH}$ radicals is the primary cause for the overall decrease in these reaction rates near the GMLI. This result was also observed in the single-shot images of Fig. 11 where the regions along the GMLI that were completely depleted of $\mathrm{OH}$ remained filled with $\mathrm{CO}$ and $\mathrm{CH}_{2} \mathrm{O}$. The lack of a significant decay in $\mathrm{CH}_{2} \mathrm{O}$ and $\mathrm{CO}$ as the turbulent flame fronts approach extinction is likely the result of turbulent transport of these intermediates from neighboring regions of the flame. The lack of $\mathrm{OH}$ radicals, and possibly $\mathrm{H}$ and $\mathrm{O}$, preclude further oxidation of $\mathrm{CH}_{2} \mathrm{O}$ and $\mathrm{CO}$. 
Full-length article submitted to Combustion and Flame

The inherent temperature dependence of the LIF signals canalso contribute to this persistence of largerCH $\mathrm{H}_{2} \mathrm{O}$ and $\mathrm{CO}$ LIF signals within the zone of influence of the product stream. In the laminar flame calculations for the lean premixed flame in Fig. 5, we showed that the peak values of the $\mathrm{CH}_{2} \mathrm{O}$ and $\mathrm{CO}$ LIF signals are shifted towards lower temperatures relative to the locations of the corresponding peak mole fractions. This inherent low-temperature bias of the LIF signals may temper their rates of decay as the flame approaches the GMLI and the peak temperature decreases. We evaluate the extent of this effect by comparing the decays of the peak values of $\mathrm{OH}, \mathrm{CH}_{2} \mathrm{O}$ and $\mathrm{CO}$ mole fractions with those of the corresponding peak LIF signals in a series of strained laminar flame calculations for $\varphi_{u}=\varphi_{b}=0.7$ and $T_{b}=1850 \mathrm{~K}$. The LIF signals are simulated using the same approach described in Section 2.4. As the strain rate increases, the flame front enters the zone of influence of the product stream for $\Delta_{f}<1.75 \mathrm{~mm}$ and the peak values decay. Figure 15 shows the calculations of the normalized peak $\mathrm{OH}, \mathrm{CH}_{2} \mathrm{O}$ and $\mathrm{CO}$ mole fractions and corresponding LIF signals as a function of the distance of the flame fronts from the gas stagnation plane.All of these quantities are normalized with respect to the corresponding values in an unstrained laminar flame. The decay of the peak OH LIF signal with decreasing $\Delta_{f}$ in Fig. 15 is in good agreement with that of the computed peak $\mathrm{OH}$ mole fraction and is similar to the decay of the conditional average of $\mathrm{OH}_{\mathrm{o}}$ in Fig. 14.For $\mathrm{CO}$ and $\mathrm{CH}_{2} \mathrm{O}$, the peak mole fractions decay faster than the respective LIF signals. This effect is significantly more pronounced for $\mathrm{CH}_{2} \mathrm{O}$ LIF than for CO LIF because of the stronger temperature dependence of the $\mathrm{CH}_{2} \mathrm{O}$ LIF signal. Although the LIF temperature dependence contributes somewhat to the observed slower decay of the $\mathrm{CH}_{2} \mathrm{O}$ and $\mathrm{CO}$ LIF signals in the zone of influence of the product stream, it does not explain the extensive persistence of the $\mathrm{CH}_{2} \mathrm{O}$ and CO LIF signals observed in Fig. 14 as $\mathrm{OH}$ disappears and the turbulent flame extinguishes near the GMLI.

This analysis supports the conclusion that much of the excess $\mathrm{CH}_{2} \mathrm{O}$ and $\mathrm{CO}$ LIF signals near the GMLI arise from turbulent transport of these species. In strained laminar premixed flames (Fig. 6), on the other hand, the $\mathrm{CH}_{2} \mathrm{O}$ and $\mathrm{CO}$ mole fractions decrease along with the $\mathrm{OH}$ mole fraction as the flames approach extinction, although $\mathrm{CH}_{2} \mathrm{O}$ decays less rapidly than $\mathrm{CO}$ and $\mathrm{OH}$. Thus, the comparison of these profiles between laminar and turbulent conditions highlights a case in which the similarity of flame structure is violated.

The response of the turbulent flames within the zone of influence of the product stream depends on the stoichiometry of the reactant and product streams. We analyze the effects ofstoichiometry on the response of the $\mathrm{CO}+\mathrm{OH}$ reaction rate in the near $\left(\Delta_{f}<1.75\right)$ and far $\left(\Delta_{f} \geq 1.75 \mathrm{~mm}\right)$ zones with respect 
Full-length article submitted to Combustion and Flame

to the separation distance of the flame front from the GMLI. For conciseness, the analysis is limited to the $\mathrm{CO}+\mathrm{OH}$ reaction rate, but similar results are obtained for the $\mathrm{CH}_{2} \mathrm{O}+\mathrm{OH}$ reaction rate since the effect of $\mathrm{OH}$ radical depletion is common to both reactions, as shown in Figs. 14a and 14b. Figure 16 shows PDFs of $k_{\mathrm{CO}+O H}^{\max }$ for three turbulent premixed flames $\left(\varphi_{u}=0.6,0.8\right.$ and 1.0) and two product stream equivalence ratios $\left(\varphi_{b}=0.7\right.$ and 1.0). The values of $k_{C O+O H}^{\max }$ are normalized with respect to the corresponding ensemble-averaged value for $\Delta_{f} \geq 1.75 \mathrm{~mm}$.Figures $16 \mathrm{a}$ and $16 \mathrm{~b}$ comparePDFs of $k_{\mathrm{CO}+O H}^{\max }$ conditional on $\triangle_{f}$ being greater and smaller than $1.75 \mathrm{~mm}$, respectively.For $\Delta_{f} \geq 1.75 \mathrm{~mm}$ (Fig. 16a), the distributions of $k_{\mathrm{CO}+O H}^{\max }$ for lean and stoichiometric products are approximatelythe same. This resultconfirms thatthe reaction rates in the far zone are not affected by the counterflowing combustion products since the flame front is sufficiently far from the GMLI.In addition, the distribution of $k_{\mathrm{CO}+\mathrm{OH}}^{\max }$ broadensinthe leaner flames, indicating that turbulencehasa stronger effect on the reaction rates of leaner flames, as expectedon the basis of theirlarger Karlovitz numbers. The PDFs of $k_{\mathrm{CO}+O H}^{\max }$ in Figure $16 \mathrm{~b}$ show that the distributions of $k_{\mathrm{CO}+O H}^{\mathrm{max}}$ conditioned on $\Delta_{f}<1.75 \mathrm{~mm}$ areshifted toward smaller values than the corresponding PDFs for the far zone in Fig. 16a.This shiftincreases for leaner reactant mixtures and counterflowing products. Partial-extinction characterized by low values of $k_{\mathrm{CO}+O H}$ is more likely in the presence of a lean product stream. Although localized extinction also occurs near the GMLI for a stoichiometric product stream, the PDFs for $\varphi_{b}=1.0$ in Fig. $16 \mathrm{~b}$ do not show as large a shift towards low values of $\mathrm{C}_{\mathrm{CO}+O H}^{\max }$. This result indicates that there is a relatively low probability of partial extinctionand the localized extinction is abrupt for $\varphi_{b}=1.0$. The effect of $\varphi_{b}$ on $k_{C O+O H}^{\max }$ is more important in the leanest $\left(\varphi_{u}=0.6\right)$ of the three turbulent premixed flames in Fig. 16b, suggesting that the turbulent flame brush of such a flame is the most exposed to the counterflowing products, asfurther elaborated in Section 3.5.

The overall effects of the reactant and product stream stoichiometries on the turbulent flame are very sensitive to the proximity of the flame front to the GMLI.If the flame front is in the far zone, the interaction with the product stream is minimal and the reaction rates are relatively insensitive to variations in the equivalence ratio.However, the stratification between reactant and product streams becomes significant when the flame fronts cross into the zone of influence near the GMLI.In this case, the equivalence ratios determine the extinction mode (abrupt vs.smooth) as well as the probability of localized extinction..

\subsection{Role of product stoichiometry on the reaction progress variable}


Full-length article submitted to Combustion and Flame

The effects of reactant-product stratification on the mean reaction progress variable of the turbulent flames areinvestigated with respect to variations in the stoichiometries of the reactant and product streams. The analysis was performed for the flow conditions and the range of reactant and product equivalence ratiosreported in Table 1.Following the same approach as in Ref. [26], we define a binary progress variable, $c$, tobe zero in the reactants and unity inregions containing products from the turbulent flame. The progress variableis determined using the OH LIF images to identify the boundary betweenreactants and flame products, as demonstrated in Fig. 10.In Fig. 17, mean progress variableprofiles for a lean $\left(\varphi_{u}=0.6\right)$ turbulent premixed flame arecontrasted with those of the stoichiometric premixed flameforlean-to-rich $\left(\varphi_{b}=0.7\right.$-to-1.2) streams of combustion products. They are plotted as a function of the axial distance from the GMLI, $\Delta$ (Fig. 2b). The mean progress variable representsthe probability that turbulent flame products are located at a distance $\Delta$ from the GMLI.It is indicative of the extent of separation of the turbulent flame brush from the GMLI and thus from the product stream.Additionally, as demonstrated in Section 3.4, depletion of the OH LIF signal along the GMLI correlates with localized extinction and, so, the OH LIF-based progress variable, $c$, can also be employed to quantify the amount of localized extinction at the GMLI. Forintermittent localized extinction along the GMLI, the conditional mean progress variable is less than unity and the probability of extinction at the GMLI is given byits complement to unity, $1-<_{C} \mid \Delta=0>$.

The lean premixed flame $\left(\varphi_{u}=0.6\right)$ strongly interacts with the stream of combustion products and is therefore very sensitive to the composition of the product stream. Near the GMLI, the amount of localized extinction varies quite substantially as a function of $\varphi_{b}$ : from nearly no extinction when $\varphi_{b}=1.2$ to a probability of localized extinction of approximately $75 \%$ when $\varphi_{b}=1.0$. The flame is significantly enhanced by both lean and rich combustion products, with rich products having a stronger supporting effect on the burning rate than lean products. The effects of the product stream stoichiometry are the strongest within a couple of millimeters from the GMLI where the profiles of the mean progress variable vary the most as a function of $\varphi_{b}$. The mean progress variable of the stoichiometric premixed flame, on the other hand,shows very little sensitivity to variations in the stoichiometry of the product stream. Accordingly, the mean progress variable profiles for stoichiometric flame are only shown for $\varphi_{b}=0.7$, 1.0 and 1.2.Near the GMLI,variations are small and, away from the GMLI, these three profiles are identical, suggesting that the flame is self-sustained. Thestoichiometric turbulent premixed flame stands sufficiently far away from the GMLI because of the larger flame speed and, as a result, it is not significantly affected by the composition of the product stream. 
Full-length article submitted to Combustion and Flame

The contrasting behavior of the lean and stoichiometric flames in Fig. 17depends on both the probability of localized extinction and the ignitability of the reactants by the hot product stream. Note that no attempt was made to force the ignition of the premixed flames with an external source of heat; ignition of the flames was only permitted by mixing of the reactants with the product stream.The effect of product stream temperature on the reactant ignitability was previously studied for a single product stream composition of $\varphi_{b}=1.0$ [26].However, the effect of product stream stoichiometry on the ignitability must also be considered.In Sections 3.1 and 3.2, we showed that the ignition of premixed flames by the combustion product stream is enhanced for product equivalence ratios away from stoichiometric conditions. These observations are consistent with the behavior of the lean $\left(\varphi_{u}=0.6\right)$ premixed flamein the vicinity of the GMLIin Fig. 17:the lower ignitability of lean reactants by a stoichiometric product streamcontributes to the low probability of lean flame fronts near the GMLI.In contrast, the rich and lean product streams increase the ignitability of the lean reactants and thereby support the presence ofa lean flame front near the GMLI. The presence of flame fronts away from the GMLI and outside the zone of influence of the product stream remainsrestrained by the ability of the premixed flames to compete with the strong adverse bulk strain rate.

These effects are further analyzed for a broader range of reactant stoichiometries in Fig. 18 where the mean progress variable profiles of lean-to-rich turbulent premixed flames $\left(\varphi_{u}=0.5,0.7,1.0,1.1\right.$ and 1.2) are compared for lean $\left(\varphi_{b}=0.7\right)$, stoichiometric $\left(\varphi_{b}=1.0\right)$ and rich $\left(\varphi_{b}=1.2\right)$ streams of combustion products.Relative to the stoichiometric product stream case $\left(\varphi_{b}=1.0\right)$, the lean $\left(\varphi_{b}=0.7\right)$ and rich $\left(\varphi_{b}=1.2\right)$ products enhance the combustion of all the turbulent premixed flames such that the probability of localized extinction near the GMLI decreases and the turbulent flame brush extends further from the GMLI. For $T_{b}=1850 \mathrm{~K}$, lean and rich products increase the ignitibility of reactants for all stoichiometries (Fig. 8). The mean progress variable of the stoichiometric flame is always the largest, indicating that none of the lean and rich premixed flames extend as far from the GMLI as the stoichiometric flame. The mean progress variable profiles for the lean and rich premixed flames have a much stronger dependence on the product stream stoichiometry than that of the stoichiometric flame. Lean combustion products strongly enhance the rich premixed flames, which aremuch weaker in the presence of a stoichiometric product stream. For example, the entire mean progress variable profile for the rich premixed flame $\left(\varphi_{u}=1.2\right)$ is near zero for $\varphi_{b}=1.0$, indicating that the flame is mostly extinguished. However, combustion of these rich reactants is supported by the lean product $\operatorname{stream}\left(\varphi_{b}=0.7\right)$, resulting in a robust flame with almost no extinction, as indicated by the near unity 
Full-length article submitted to Combustion and Flame

value of the progress variable at the GMLI in the left plot of Fig. 18. Reciprocally, lean premixed flames are well sustained by a rich product stream, as seen in the right plot of Fig. 18. The combined results in Figs.17 and 18 demonstrate conclusively the substantial sensitivity of turbulent premixed combustion to the stoichiometry of the product stream, with thelaminar computations helping toexplain the observed flame behaviors in terms of their ignition and extinction limits.

\section{Conclusionand implications}

The interaction of a turbulent stream of premixed reactants at ambient temperature with hightemperature combustion products was studied in the counterflow configuration. The focus was on the effects of the stoichiometry, which was varied in either stream independently of the other to mimic stratification effects occurring in practical systems. The principal conclusions follow:

1) Qualitatively, the global ignitability and stability of turbulent flames, regardless of the stoichiometry of the reactant mixture, are facilitated strongly by lean combustion products, mildly by rich products and most limited in the presence of stoichiometric products.

2) These results are in part confirmed by detailed measurements of the structure of the turbulent flames using $\mathrm{CH}_{2} \mathrm{O}+\mathrm{OH}$ and $\mathrm{CO}+\mathrm{OH}$ reaction rates. These measurements showed the influence of the stoichiometry of the product stream when the turbulent brush is positioned within a "zone of influence" that extends approximately a couple of millimeters from the Gas Mixing Layer Interface (GMLI) between the two streams.

3) In particular, a decrease in local $\mathrm{CH}_{2} \mathrm{O}+\mathrm{OH}$ and $\mathrm{CO}+\mathrm{OH}$ reaction rates coincided with the depletion of $\mathrm{OH}$ radicals in the vicinity of the combustion product stream. In regions where partial or complete localized extinction occurred, neither $\mathrm{CH}_{2} \mathrm{O}$ nor $\mathrm{CO}$ decayed appreciably as a result of turbulent transport of these intermediates from neighboring regions of the flame. The $\mathrm{CH}_{2} \mathrm{O}+\mathrm{OH}$ and $\mathrm{CO}+\mathrm{OH}$ reactions appeared to be more readily quenched in the presence of products of combustion from a stoichiometric flame whereas they were favored by lean combustion products.

4) The effect of the product stream composition is confirmed by calculations on laminar flames of the same composition, showing that the product stream composition affects the extinction and its mode (smooth or abrupt) within a zone of influence close to the gas stagnation plane comparable to that found in turbulent flames. As a result, laminar flame calculations provide remarkable 
Full-length article submitted to Combustion and Flame

guidance in the interpretation of the present results with the fundamental structure of a laminar flame not being disrupted by the turbulence even in the presence of localized extinction.

5) Even though under some conditions the turbulent flame is locally extinguished and has a complex morphology in instances of flame folding, its structure is not fundamentally altered with respect to the laminar counterpart, except for the inevitable broadening of profiles as a result of turbulent transport.

\section{Acknowledgments}

The authors gratefully acknowledge the support of the American Chemical Society (ACS) through Grant PRF\#46991-AC9 and of NSF (Grant \#1060762.1.D1692.652001, Dr. Arvind Atreya, Program Director, Grant \# CBET-1033204 and -14003433, Dr. Ruey-Hung Chen, Program Director) and the US Department of Energy, Office of Basic Energy Sciences, Division of Chemical Sciences, Geosciences, and Biosciences. Sandia National Laboratories is a multiprogram laboratory operated by Sandia Corporation, a Lockheed Martin Company, for the US Department of Energy under contract DE-AC0494-AL85000. 


\section{References}

1 Dunn-Rankin, D., "Lean Combustion: Technology and Control”, Academic Press, USA, 2008.

2 Masri, A, "Partial Premixing and Stratification in Turbulent Flames", Proc. Combust. Inst. 35 (2015) 1115-1136.

3 Pasquier, N., Lecordier, B., Trinité, M., Cessou, A., “An Experimental Investigation of Flame Propagation through a Turbulent Stratified Mixture”, Proc. Combust. Inst. 31 (2007) 1567-1574.

4 Barlow, R.S., Wang, G.-H., Anselmo-Filho, P., Sweeney, M.S., Hochgreb, S., “Application of Raman/Rayleigh/LIF diagnostics in turbulent stratified flames”, Proc. Combust. Inst. 32 (2009) 945-953.

5 Robin, V., Mura, A., Champion, M., Degardin, O., Renou, B., Boukhalfa, M., "Experimental and numerical analysis of stratified turbulent V-shaped flames", Combust. Flame 153 (2008) 288-315.

6 Galizzi, C., Escudié, D., "Experimental analysis of an oblique turbulent flame front propagating in a stratified flow", Combust. Flame 157 (2010) 2277-2285.

7 Vena, P.C., Deschamps, B., Smallwood, G.J., Johnson, M.R., “Equivalence ratio gradient effects on flame front topology in a stratified iso-octane/air turbulent V-lame”, Proc. Combust. Inst. 33 (2011) 1551-1558.

8 Sweeney, M.S., Hochgreb, S., Dunn, M.J., Barlow, R.S., "The structure of turbulent stratified and premixed methane/air flames: I. Non-swirling flows", Combust. Flame 159 (2012) 2896-2911.

9 Chaudhuri, S., Kostka, S., Renfro, M.W., Cetegen, B.M., "Blowoff Dynamics of Bluff Body Stabilized Turbulent Premixed Flames”, Combust. Flame 157 (2010) 790-802.

10 Bonaldo, A., Kelman, J.B., "Experimental annular stratified flames characterization stabilized by weak swirl”, Combust. Flame 156 (2009) 750-762.

11 Sweeney, M.S., Hochgreb, S., Dunn, M.J., Barlow, R.S., "The structure of turbulent stratified and premixed methane/air flames: II. Swirling flows”, Combust. Flame 159 (2012) 2912-2929.

12 Seffrin, F., Fuest, F., Geyer, D., Dreizler, A., "Flow field of a new series of turbulent premixed stratified flames", Combust. Flame 157 (2010) 384-396. 
Full-length article submitted to Combustion and Flame

13 Pires Da Cruz, A., Dean, A.M., Grenda, J.M., "A numerical study of the laminar flame speed of stratified methane/air flames", Proc. Combust. Inst. 28 (2000) 1925-1932.

14 Marzouk, Y.M., Ghoniem, A.F., Najm, H.N., "Dynamic Response of Strained Premixed Flames to Equivalence Ratio Gradients” Proc. Combust. Inst. 28 (2000) 1859-1866.

15 Kang, T., Kyritsis, D.C., "Departure from quasi-homogeneity during laminar flame propagation in lean, compositionally stratified methane-air mixtures”, Proc. Combust. Inst. 31 (2007) 1075-1083.

16 Kang, T., Kyritsis, D.C., "Phenomenology of methane flame propagation into compositionally stratified, gradually richer mixtures”, Proc. Combust. Inst. 32 (2009) 979-985.

17 Richardson, E.S., Granet, V.E., Eyssartier, A., Chen, J.H., "Effects of equivalence ratio variation on lean, stratified methane-air laminar counterflow flames", Combust. Theory Model. 14 (2010) 775792.

18 Kuenne, G., Seffrin, F., Fuest, F., Stahler, T., Ketelheum, A., Geyer, D., Janicka, J., Dreizler, A., "Experimental and numerical analysis of a lean premixed stratified burner using 1D Raman/Rayleigh scattering and large eddy simulation” Combust. Flame 159 (2012) 2669-2689.

19 Garrido-López, D., Sarkar, S., "Effect of imperfect premixing coupled with hydrodynamic instability on flame propagation", Proc. Combust. Inst. 30 (2005) 621-628.

20 Pera, C., Chevillard, S., Reveillon, J., "Effects of residual burnt gas heterogeneity on early flame propagation and on cyclic variability in spark-ignitied engines”, Combust. Flame 160 (2013) 10201032.

21 Hélie, J., Trouvé, A., "Turbulent flame propagation in partially premixed combustion" Proc. Combust. Inst. 27 (1998) 891-898.

22 Jiménez, C., Cuenot, B., Poinsot, T., Haworth, D., "Numerical simulation and modeling for lean stratified propane-air flames", Combust. Flame 128 (2002) 1-21.

23 Vena, P.C., Deschamps, B., Guo, H., Smallwood, G.J., Johnson, M.R., "Heat Release Rate Variations in a Globally Stoichiometric, Stratified Iso-Octane/Air Turbulent V-Flame”, Combust. Flame 162 (2015) 944-959.

24 Mastorakos, E., Taylor, A.M.K., Whitelaw, J.H., "Extinction of Turbulent Counterflow Flames with Reactants diluted by Hot Products”, Combust. Flame 102 (1995) 101-114. 
Full-length article submitted to Combustion and Flame

25 Coriton, B., Frank, J.H., Hsu, A.G., Smooke, M.D., Gomez, A., "Effect of quenching of the oxidation layer in highly turbulent counterflow premixed flames”. Proc. Combust. Inst. 33 (2011) 1647-1654.

26 Coriton, B., Frank, J.H., Gomez, A., "Effects of strain rate, turbulence, reactant stoichiometry and heat losses on the interaction of turbulent premixed flames with stoichiometric counterflowing combustion products”, Combust. Flame 160 (2013) 2442-2456.

27 Coppola, G., Coriton, B., Gomez, A., "Highly turbulent counterflow flames: a laboratory scale benchmark for practical systems", Combust. Flame 156 (2009) 1834-1843.

28 Boxx, I., Stöhr, M., Carter, C., Meier, W., "Temporally Resolved Planar Measurements of Transient Phenomena in a Partially Premixed Swirl Flame in a Gas Turbine Model Combustor", Combust. Flame 157 (2010) 1510-1525.

29 Meier, W., Duan, X.R., Weigand, P., "Investigations of swirl flames in gas turbine model combustor II. Turbulence-chemistry interactions", Combust. Flame 144 (2006) 225-236.

30 Nogenmyr, K.-J., Fureby, C., Bai, X.S., Peterson, P., Linne, M., "Large Eddy Simulation and Laser Diagnostic Studies on a Low Swirl Stratified Premixed Flame”, Combust. Flame 156 (2009) 25-36.

31 Sengissen, A.X., Van Kampen, J.F., Huls, R.A., Stoffels, G.G.M., Kok, J.B.W., Poinsot, T.J., "LES and experimental studies of cold and reacting flow in a swirled partially premixed burner with and without fuel modulation", Combust. Flame 150 (2007) 40-53.

32 Roquemore, W.M., Shouse, D., Burrus, D., Johnson, A., Cooper, C., Duncan, B., Hsu, K.-Y., Katta, V.R., Sturgess, G.J., Vihinen, I., “Trapped vortex combustor concept for gas turbine engines", AIAA paper No. 2001-0483, AIAA 39 ${ }^{\text {th }}$ Aerospace Sciences Meeting \& Exhibit, Reno, Nevada, January 8-11, 2001.

33 Bruno, C., Losurdo, M., “The Trapped Vortex Combustor: an Advanced Combustion Technology for Aerospace and Gas Turbine Applications", Advanced Combustion and Aerothermal Technologies, NATO Science for Peace and Security Series C: Environmental Security (2007) 365384.

34 Hong, S., Speth, R.L., Shanbhogue, S.J., Ghoniem, A.F., "Examining flow-flame interaction and the characteristic stretch rate in vortex-driven combustion dynamics using PIV and numerical simulation", Combust. Flame 160 (2013) 1381-1397. 
Full-length article submitted to Combustion and Flame

35 Ruggles, A., Kelman, J., “A Gas Turbine Combustor for Instability Research and LES Validation: Methods and Mean Results”, Combust. Sci. Tech. 186 (2014) 313-331.

36 Peters, N., “Turbulent Combustion”, Cambridge Monographs on Mechanics, Cambridge University Press, Cambridge, UK, 2000.

37 Libby, P.A., Williams, F.A., "Strained Premixed Laminar Flames Under Non-Adiabatic Conditions", Combust. Sci. Tech. 31 (1983) 1-42.

38 Darabiha, N., Candel, S.M., Marble, F.E., "The Effect of Strain Rate on a Premixed Laminar Flame”, Combust. Flame 64 (1986) 203-217.

39 Lauvergne, R., Egolfopoulos, N., "Unsteady response of $\mathrm{C}_{3} \mathrm{H}_{8}$ /air laminar premixed flames submitted to mixture composition oscillations", Proc. Combust. Inst. 28 (2000) 1841-1850.

40 Zhou, R., Hochgreb, S., "The behaviour of laminar stratified methane/air flames in counterflow", Combust. Flame 160 (2013) 1070-1082.

41 Coriton, B., Smooke, M.D., Gomez, A., "Effect of the composition of the hot product stream in the quasi-steady extinction of strained premixed flames", Combust. Flame 157 (2010) 2155-2164.

42 Najm, H.N., Paul, P.H., Mueller, C.J., Wyckoff, P.S., "On the Adequacy of Certain Experimental Observables as measurements of Flame Burning Rate”, Combust. Flame 113 (1998) 312-332.

43 Paul, P.H., Najm, H.B., "Planar Laser-Induced Fluorescence Imaging of Flame Heat Release Rate”, Proc. Combust. Inst. 27 (1998) 43-50.

44 Gazi, A., Vourliotakis, G., Skevis, G., Founti, M.A., “Assessment of chemical markers for HeatRelease Rate Correlations in Laminar Premixed Flames”, Comb. Sci. Technol. 185 (2013) 14821508.

45 Coppola, G., Gomez, A., "Experimental investigation on a turbulence generation system with highblockage plates", Exp. Therm. Fluid Sci. 33 (2009) 1037-1048.

46 Pettit, M.W.A., Coriton, B., Gomez, A., Kempf, A.M., "Large-Eddy Simulation and experiments on non-premixed highly turbulent opposed jet flows”, Proc. Combust. Inst. 33 (2011) 1391-1399.

47 Kee, R.J., et al., CHEMKIN Collection, Release 4.1.1, Reaction Design, Inc., San Diego, CA (2007). 
Full-length article submitted to Combustion and Flame

48 San Diego Mechanism web page, Mechanical and Aerospace Engineering (Combustion Research), University of California at San Diego (http://combustion.ucsd.edu).

49 Peters, N., "The turbulent burning velocity for large-scale and small-scale turbulence", J. Fluid Mech. 384 (1999) 107-132.

50 Poinsot, T., Veynante, D., Candel, S., “Quenching Process and Premixed Turbulent Combustion Diagrams”, J. Fluid Mech. 228 (1991) 561-606.

51 Frank, J.H., Kaiser, S.A., Long, M.B., "Reaction-Rate, Mixture-Fraction, and Temperature Imaging in Turbulent Methane/Air Jet Flames”, Proc. Combust. Inst. 29 (2002) 2687-2694.

52 Rehm, J.E., Paul, P.H., “Reaction Rate Imaging”, Proc. Combust. Inst. 28 (2000) 1775-1782.

53 Amantini, G., Frank, J.H., Gomez, A., "Experiments on standing and traveling edge flames around flame holes", Proc. Combust. Inst. 30 (2005) 313-321.

54 Balachandran, R., Ayoola, B.O., Kaminski, C.F., Dowling, A.P., Mastorakos, E., “Experimental Investigation of the Nonlinear Response of Turbulent Premixed Flames to Imposed Inlet Velocity Oscillations", Combust. Flame 143 (2005) 37-55.

55 Ayoola, B.O., Balachadran, R., Frank, J.H., Mastorakos, E., Kaminski, C.F., "Spatially resolved heat release rate measurements in turbulent premixed flames", Combust. Flame 144 (2006) 1-16.

56 Dunn, M.J., Masri, A.R., Bilger, R.W., Barlow, R.S., "Finite rate chemistry effects in highly sheared turbulent premixed flames", Flow Turb. Combust. 85 (2010) 621-648.

57 Gordon, R.L., Masri, A.R., Mastorakos, E., "Heat Release Rate as Represented by [OH] x [CH $\mathrm{CH}_{2} \mathrm{O}$ and its Role in Autoignition", Combust. Theory Model. 13:4 (2009) 645-670.

58 Kariuki, J., Dowlut, A., Yuan, R., Balachandran, R., Mastorakos, E., "Heat Release Imaging in Turbulent Premixed Methane-Air Flames Close to Blow-Off', Proc. Combust. Inst. 35 (2015) 1443-1450.

59 Tamura, M., Berg, P.A., Harrington, J.E., Luque, J., Jeffries, J.B., Smith, G.P., Crosley, D.R., "Collisional Quenching of $\mathrm{CH}(\mathrm{A}), \mathrm{OH}(\mathrm{A})$, and $\mathrm{NO}(\mathrm{A})$ in low pressure hydrocarbon flames", Combust. Flame 114 (1998) 502-514. 
Full-length article submitted to Combustion and Flame

60 Settersten, B., Dreizler, A., Farrow, R.L., "Temperature and species-dependent quenching of CO sigma $(\mathrm{v}=0)$ probed by two-photon laser induced fluorescence using a picosecond laser", J. Chem. Phys. 117 (2002) 3173-3179.

61 Di Rosa, M.D., Farrow, R.L., "Cross sections of photoionization and ac Stark shift measured from Doppler-free $B \leftarrow X(0,0)$ excitation spectra of CO”, J. Opt. Soc. Am. B 16 (1999) 861-870.

62 Judge, R.H., Clouthier, D.J., “AsyrotWin: a 32-bit Windows version of Asyrot, a program for the analysis of high resolution singlet-singlet band spectra of asymmetric tops", Comput. Phys. Commun. 135 (2001) 293-311.

63 Coriton, B., Zendehdel, M., Ukai, S., Kronenburg, A., Stein, O.T., Im, S.-K., Gamba, M., Frank, J.H., "Imaging measurements and LES-CMC modeling of a partiallypremixed turbulent dimethyl ether/air jet flame”, Proc. Combust. Inst. 35 (2015) 1251-1258.

64 Peters, N., "Laminar flamelet concept in turbulent combustion", Proc. Combust. Inst. 21 (1986) 1231-1250.

65 Pitsch, H., Chen, M., Peters, N., "Unsteady Flamelet Modeling of Turbulent Hydrogen-Air Diffusion Flames", Proc. Combust. Inst. 27 (1998) 1057-1064. 
Full-length article submitted to Combustion and Flame

\section{Tables}

Table 1 - Experimental conditions.

\begin{tabular}{l|l}
$\boldsymbol{K}_{\text {bulk }}$ & $1400 \mathrm{~s}^{-1}$ \\
\hline $\boldsymbol{R e}_{\boldsymbol{t}}$ & 1050 \\
\hline $\boldsymbol{T}_{\boldsymbol{b}}$ & $1850 \mathrm{~K}$ \\
\hline $\boldsymbol{\varphi}_{u}$ & $0.5-1.2$ \\
\hline $\boldsymbol{\varphi}_{\boldsymbol{b}}$ & $0.7,1.0,1.2$
\end{tabular}

Table 2. Turbulent $\mathrm{CH}_{4} / \mathrm{O}_{2} / \mathrm{N}_{2}$ premixed flame properties for $\operatorname{Re}_{t}=1050\left(u^{\prime}=3.9 \mathrm{~m} / \mathrm{s}\right.$ and $\left.l^{\prime}=4.1 \mathrm{~mm}\right)$. For all the flames, the $\mathrm{O}_{2} / \mathrm{N}_{2}$ molar ratio is $30 / 70$.

\begin{tabular}{|c|c|c|c|c|c|c|c|}
\hline$\varphi_{u}$ & $\begin{array}{l}T_{a d} \\
(K)\end{array}$ & $\begin{array}{c}S_{L} \\
(g / h r)\end{array}$ & $\begin{array}{c}S_{L} \\
(\mathrm{~cm} / \mathrm{s})\end{array}$ & $u^{\prime} / S_{L}$ & $\begin{array}{c}l_{F} \\
(\mathrm{~mm})\end{array}$ & $I^{\prime} / l_{F}$ & $K \boldsymbol{a}_{t}$ \\
\hline 1.20 & 2522 & 302 & 74.4 & 5.2 & 0.27 & 15.3 & 3.1 \\
\hline 1.10 & 2549 & 322 & 79.1 & 4.9 & 0.25 & 16.0 & 2.7 \\
\hline 1.00 & 2534 & 324 & 79.1 & 4.9 & 0.25 & 16.1 & 2.7 \\
\hline 0.90 & 2482 & 303 & 73.5 & 5.3 & 0.26 & 15.6 & 3.1 \\
\hline 0.80 & 2390 & 268 & 64.7 & 6.0 & 0.28 & 14.5 & 3.9 \\
\hline 0.70 & 2255 & 217 & 52.1 & 7.5 & 0.32 & 12.8 & 5.7 \\
\hline 0.60 & 2076 & 156 & 37.3 & 10.5 & 0.39 & 14.0 & 10.5 \\
\hline 0.50 & 1854 & 92 & 21.7 & 18.0 & 0.57 & 7.1 & 28.5 \\
\hline
\end{tabular}


Full-length article submitted to Combustion and Flame

\section{List of Figures}

Figure 1 - Principle of a flame back-supported by combustion products. ....................................... 35

Figure 2 - Schematics of a) the turbulent counterflow burner and b) a turbulent premixed flame in

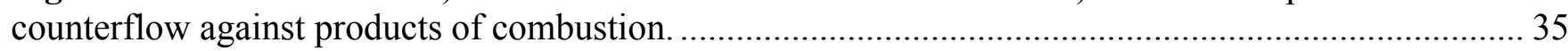

Figure 3 - Premixed flame coordinates in diagram of turbulent combustion regimes. ....................... 36

Figure 4 - Experimental configuration for a) simultaneous $\mathrm{CO} / \mathrm{OH}$ LIF and b) simultaneous $\mathrm{CH}_{2} \mathrm{O} / \mathrm{OH}$

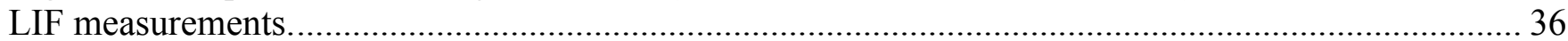

Figure 5 - a) Computed $\mathrm{OH}, \mathrm{CO}$ and $\mathrm{CH}_{2} \mathrm{O}$ mole fractions and $\mathrm{CO}+\mathrm{OH}$ and $\mathrm{CH}_{2} \mathrm{O}+\mathrm{OH}$ reaction rates, $\mathrm{kCO}+\mathrm{OH}$ and $\mathrm{kCH} 2 \mathrm{O}+\mathrm{OH}$, respectively, for a freely propagating laminar flame of equivalence ratio $\varphi_{u}=0.7$ b) Simulated $\mathrm{OH}, \mathrm{CO}$ and $\mathrm{CH}_{2} \mathrm{O}$ LIF signals and estimated reaction rates, $k C O+O H L I F$ and $k C H 2 O+O H L I F$, derived from the products of the $\mathrm{CO} / \mathrm{OH}$ LIF and $\mathrm{CH}_{2} \mathrm{O} / \mathrm{OH}$ LIF signals, respectively. Profiles are normalized by their peak values. c) Computed temperature profile. .............. 37

Figure 6 - Normalized $\mathrm{OH}, \mathrm{CO}$ and $\mathrm{CH}_{2} \mathrm{O}$ peak mole fractions and peak heat release rates for $\varphi_{b}=0.7$ and $\varphi_{u}$ equal to $0.7,1.0$ and 1.2 plotted as a function of strain rate computed using a one-dimensional counterflow model. Values are normalized with corresponding ones for unstrained laminar premixed flames. 38

Figure 7 - Computed normalized peak heat release rates to extinction as a function of their position with respect to the gas stagnation plane (GSP), $\Delta_{f}$, for $\varphi_{b}$ equal to $0.7,1.0$ and 1.2 and for $\varphi_{u}=0.7$ (left), $\varphi_{u}=1.0$ (middle) and $\varphi_{u}=1.2$ (right). Values are normalized with corresponding ones for unstrained laminar premixed flames. Vertical red dashed line indicates the approximate boundary of the zone of influence of the product stream. 38

Figure 8 - Computed smooth extinction/ignition (dotted) strain rates and abrupt extinction (solid) and ignition (dashed) strain rates for $\varphi_{u}$ equal to $0.7,1.0$ and 1.2 and for $\varphi_{b}=0.7$ (blue), $\varphi_{b}=1.0$ (black) and $\varphi_{b}=1.2$ (red). Smooth extinction/ignition strain rates correspond to $90 \%$ decrease of peak heat release rates relative to in unstrained laminar flow. 39

Figure 9 - Ignition and flame stability limits plotted in terms of $T_{b}$ and $\varphi_{b}$ for a) premixed flames of equivalence ratios $\varphi_{u}$ equal to $0.7,1.0$ and 1.2 at $K_{b u l k}=1400 / \mathrm{s}$ and b) the stoichiometric $\left(\varphi_{u}=1.0\right)$ premixed flame at $K_{\text {bulk }}=1400 / \mathrm{s}$ and 2240/s. Stable burning regime (solid); pulsing burning regime (dashed).

Figure 10 - Definition and identification of the gas mixing layer interface (GMLI) and the flame front location in a single-shot OH LIF measurement. 41

Figure 11 - Single-shot LIF measurements in the lean $\left(\varphi_{u}=0.7\right)$ turbulent premixed flame opposed to either stoichiometric $\left(\varphi_{b}=1.0\right)$ or lean $\left(\varphi_{b}=0.7\right)$ products of combustion at $T_{b}=1850 \mathrm{~K}$. a) OHLIF (top row), $\mathrm{CH}_{2} \mathrm{OLIF}$ (middle row), and reaction rate $\mathrm{kCH} 2 \mathrm{O}+\mathrm{OH}$ (bottom row), b) OHLIF (top row), $\mathrm{COLIF}$ (middle row) and reaction rate, $\mathrm{kCO}+\mathrm{OH}$ (bottom row). Reaction rates, $\mathrm{kCH} 2 \mathrm{O}+\mathrm{OH}$ and $k \mathrm{CO}+\mathrm{OH}$, are indicative of the primary heat release rate and the rate of $\mathrm{CO}$ oxidation in the flame, respectively. Red arrows indicate extinguished or partially extinguished regions along the GMLI. The reaction rates and the LIF signals were normalized with respect to their respective ensemble-averaged values computed for $\Delta_{f} \geq 1.75 \mathrm{~mm}$.

Figure 12 - Flame-normal profiles of a) OHLIF, $\mathrm{CH}_{2} \mathrm{OLIF}$, and $\mathrm{kCH} 2 \mathrm{O}+\mathrm{OH}$ interpolated along segments labeled (1), (2) and (3) in Fig. 11a; b) COLIF, OHLIF and $k C O+O H$ for the segments in 
Fig. 11b. The reaction rates and the LIF signals were normalized with respect to their respective ensemble-averaged values computed for $\Delta_{f} \geq 1.75 \mathrm{~mm}$. 43

Figure 13 - a) Mean turbulent premixed flame structure $\left(\varphi_{u}=\varphi_{b}=0.7\right)$ based on mean flame-normal profiles of LIF signals of $\mathrm{CH}_{2} \mathrm{O}, \mathrm{OH}$ and forward reaction rate of $\mathrm{CH}_{2} \mathrm{O}+\mathrm{OH}$ (solid lines), as well as LIF signals of $\mathrm{CO}, \mathrm{OH}$ and forward reaction rate of $\mathrm{CO}+\mathrm{OH}$ (dashed lines); b) PDFs of positions of peak $\mathrm{CO}$ LIF, peak $\mathrm{CH}_{2} \mathrm{O}$ LIF and peak reaction rates along the flame-normal coordinate. 44

Figure 14 - Scatter plots of normalized values of a) $k C H 2 O+O H \max$ and b) $k C O+O H \max$ as a function of $\Delta_{f}$ for the lean $\left(\varphi_{\mathrm{u}}=0.7\right)$ turbulent premixed flame opposed to lean $\left(\varphi_{b}=0.7\right)$ counterflowing combustion products. Scatter plots are overlapped with averages of a) $\mathrm{kCH} 2 \mathrm{O}+\mathrm{OHmax}$ (red), $\mathrm{CH}_{2} \mathrm{O}_{\max }$ (blue) and $\mathrm{OH}_{\mathrm{o}}$ (green) and b) $\mathrm{kCO}+\mathrm{OHmax}$ (red), $\mathrm{CO}_{\max }$ (blue) and $\mathrm{OH}_{\mathrm{o}}$ (green), conditioned on $\Delta_{f}$. Vertical red dashed line indicates the approximate boundary of the zone of influence of the product stream. 45

Figure 15 - Comparison of computed normalized peak mole fractions and LIF signals for $\mathrm{OH}, \mathrm{CO}$ and $\mathrm{CH}_{2} \mathrm{O}$ plotted as a function of the location of peak heat release rate with respect to the gas stagnation plane (GSP), $\Delta_{f}$, for $\varphi_{b}=\varphi_{u}=0.7$. Each quantity is normalized by the corresponding value in the unstrained laminar premixed flame for $\varphi_{u}=0.7$. Vertical red dashed line indicates the approximate boundary of the zone of influence of the product stream. 46

Figure 16 - PDFs of $k C O+O H \max$ for different combinations of reactant and product streams conditioned on the proximity of the turbulent flame fronts to the GMLI: a) $\Delta_{f} \geq 1.75 \mathrm{~mm}$, b) $\Delta_{f}<1.75 \mathrm{~mm}$. For each flame condition, values of $k C O+O H \max$ are normalized with respect to its ensemble-average for $\Delta_{f} \geq 1.75 \mathrm{~mm}$.

Figure 17 - Effect of product stream equivalence ratio $\varphi_{b}$ on the mean progress variable of turbulent premixed flames of equivalence ratios $\varphi_{u}=0.6$ (solid lines) and $\varphi_{u}=1.0$ (Dashed lines). Vertical red dashed line indicates the approximate boundary of the zone of influence of the product stream on the reaction rates. 48

Figure 18 - Effect of product stream equivalence ratio $\varphi_{b}$ on the $\mathrm{OH}$-based mean progress variable of turbulent premixed flames of equivalence ratios $\varphi_{u}$ equal to $0.5,0.7,1.0,1.1$ and 1.2. Vertical red dashed line indicates the approximate boundary of the zone of influence of the product stream on the reaction rates. 


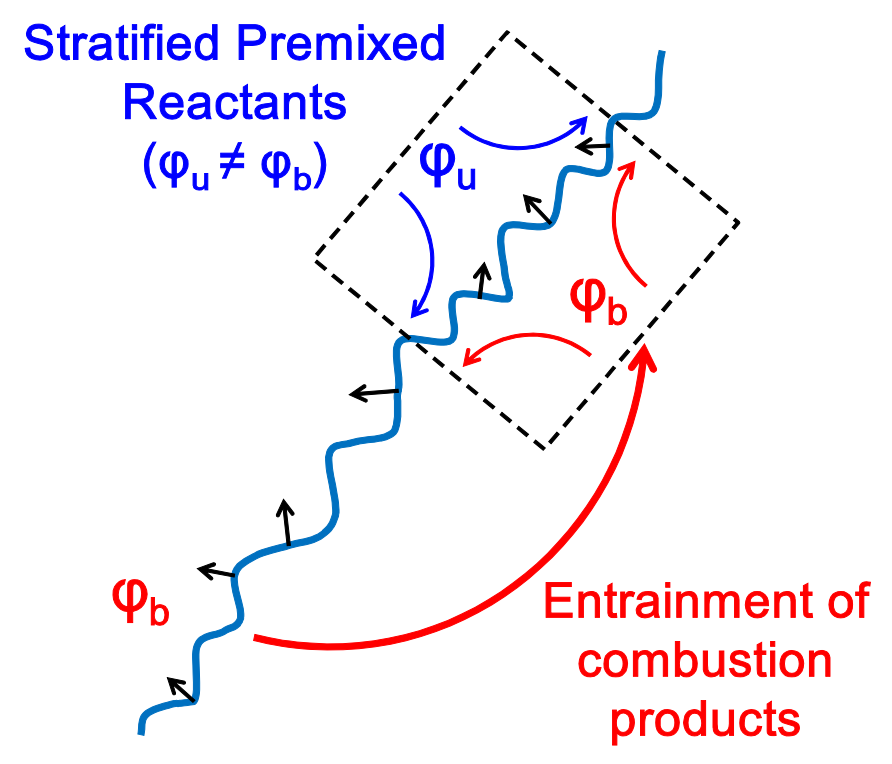

Figure 1 - Principle of a flame back-supported by combustion products.
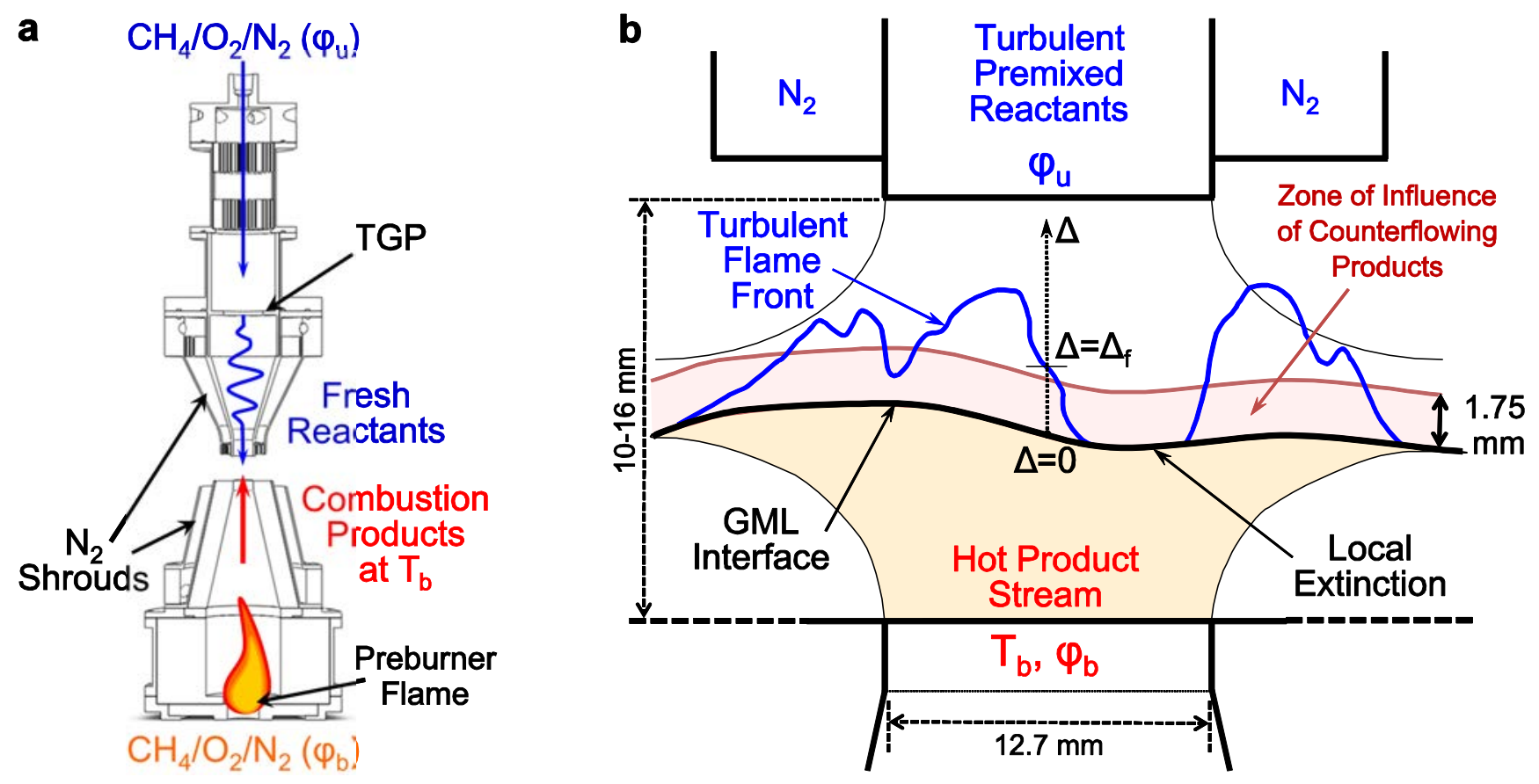

Figure 2 - Schematics of a) the turbulent counterflow burner and b) a turbulent premixed flame in counterflow against products of combustion. 
Full-length article submitted to Combustion and Flame

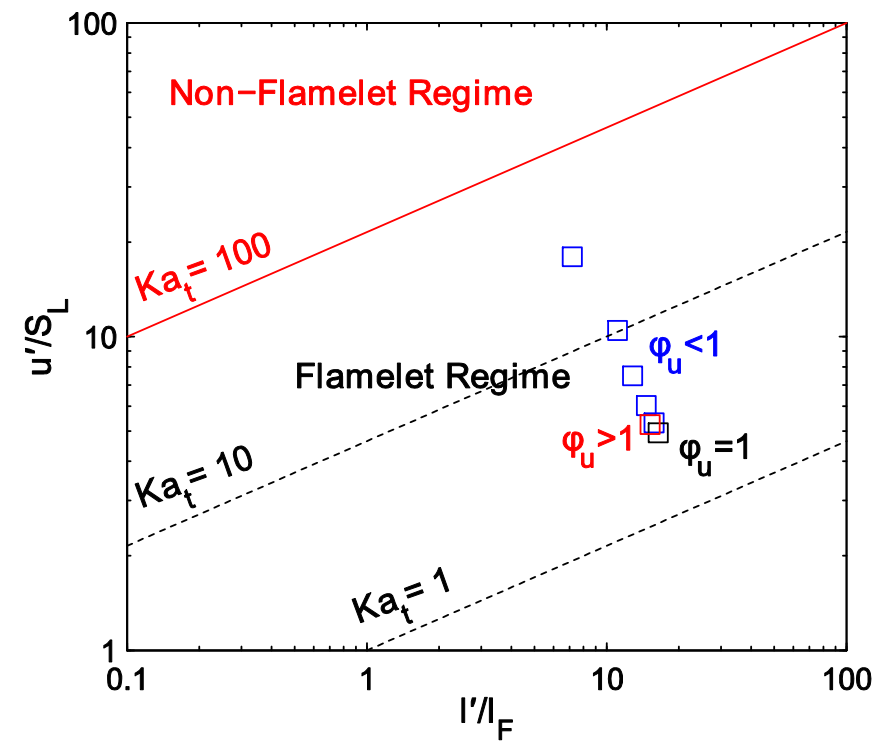

Figure 3- Premixed flame coordinates in diagram of turbulent combustion regimes.

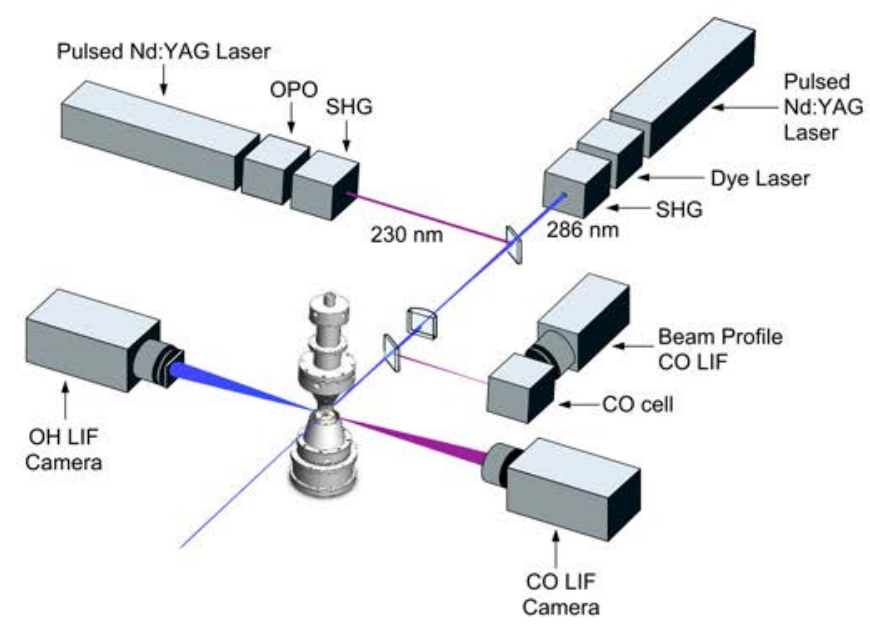

a

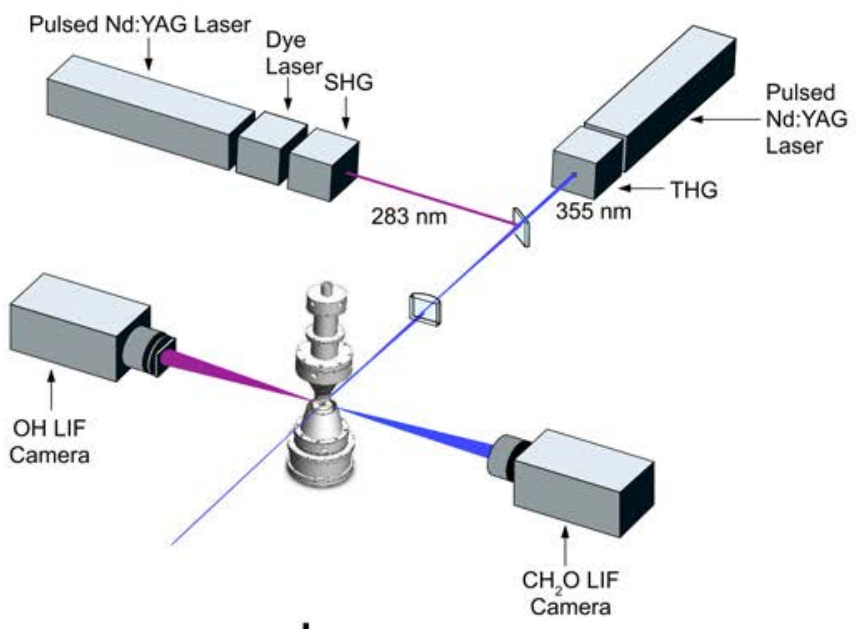

b

Figure 4 - Experimental configuration fora) simultaneous $\mathrm{CO} / \mathrm{OH}$ LIF and b) simultaneousCH $\mathrm{H}_{2} \mathrm{O} / \mathrm{OH}$ LIF measurements. 
Full-length article submitted to Combustion and Flame
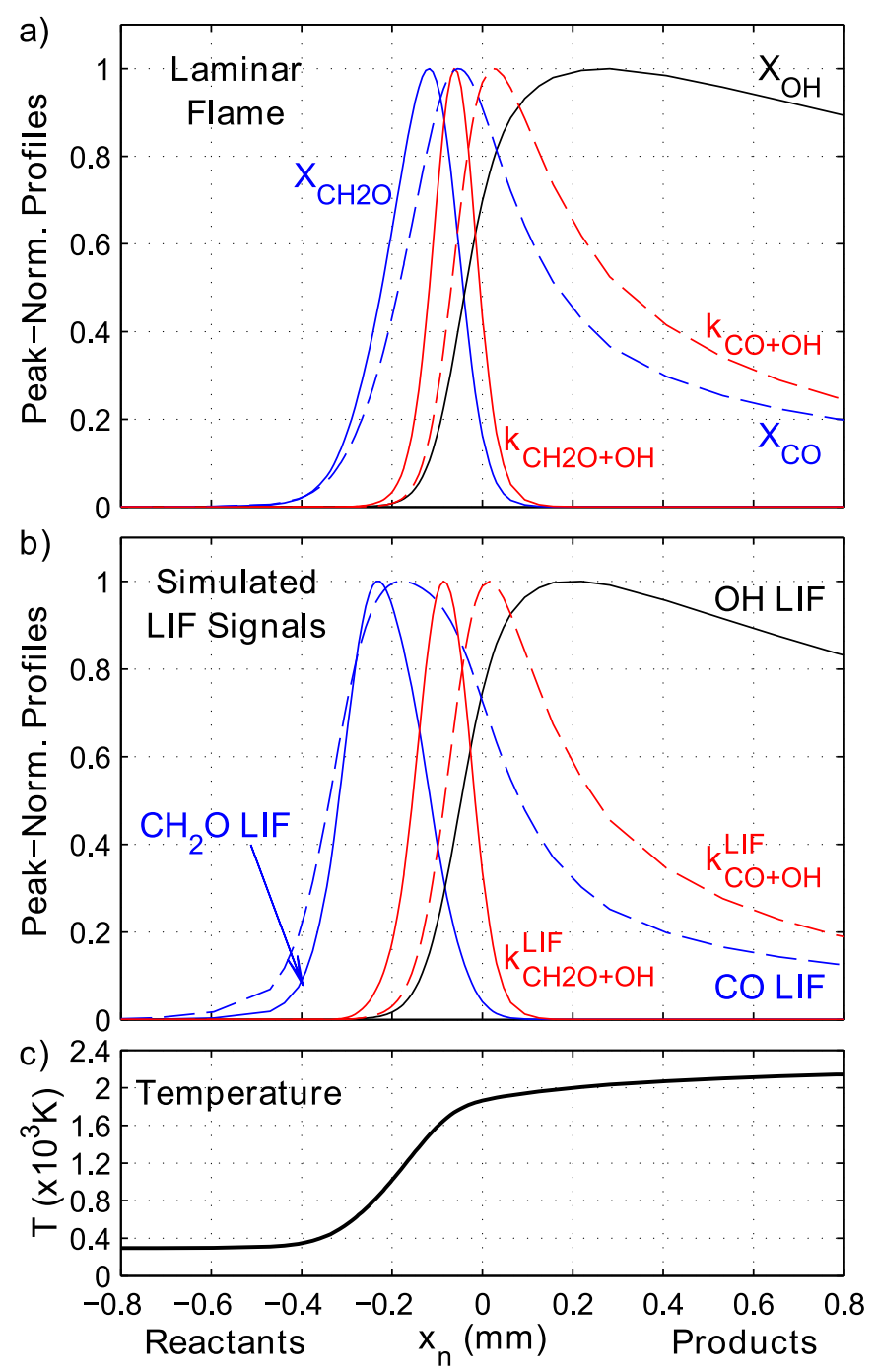

Figure 5 - a) Computed $\mathrm{OH}, \mathrm{CO}$ and $\mathrm{CH}_{2} \mathrm{O}$ mole fractions and $\mathrm{CO}+\mathrm{OH}$ and $\mathrm{CH}_{2} \mathrm{O}+\mathrm{OH}$ reaction rates, $k_{\mathrm{CO}+\mathrm{OH}}$ and $k_{\mathrm{CH} 2 \mathrm{O}+\mathrm{OH}}$, respectively, for a freelypropagating laminar flame of equivalence ratio $\varphi_{u}=0.7$ b) Simulated $\mathrm{OH}, \mathrm{CO}$ and $\mathrm{CH}_{2} \mathrm{O}$ LIF signals and estimated reaction rates, $k_{C O+O H}^{L I F}$ and

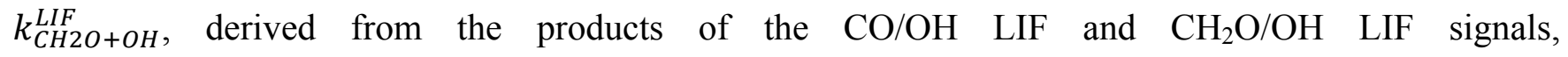
respectively.Profiles are normalized by their peak values.c) Computed temperature profile. 
Full-length article submitted to Combustion and Flame
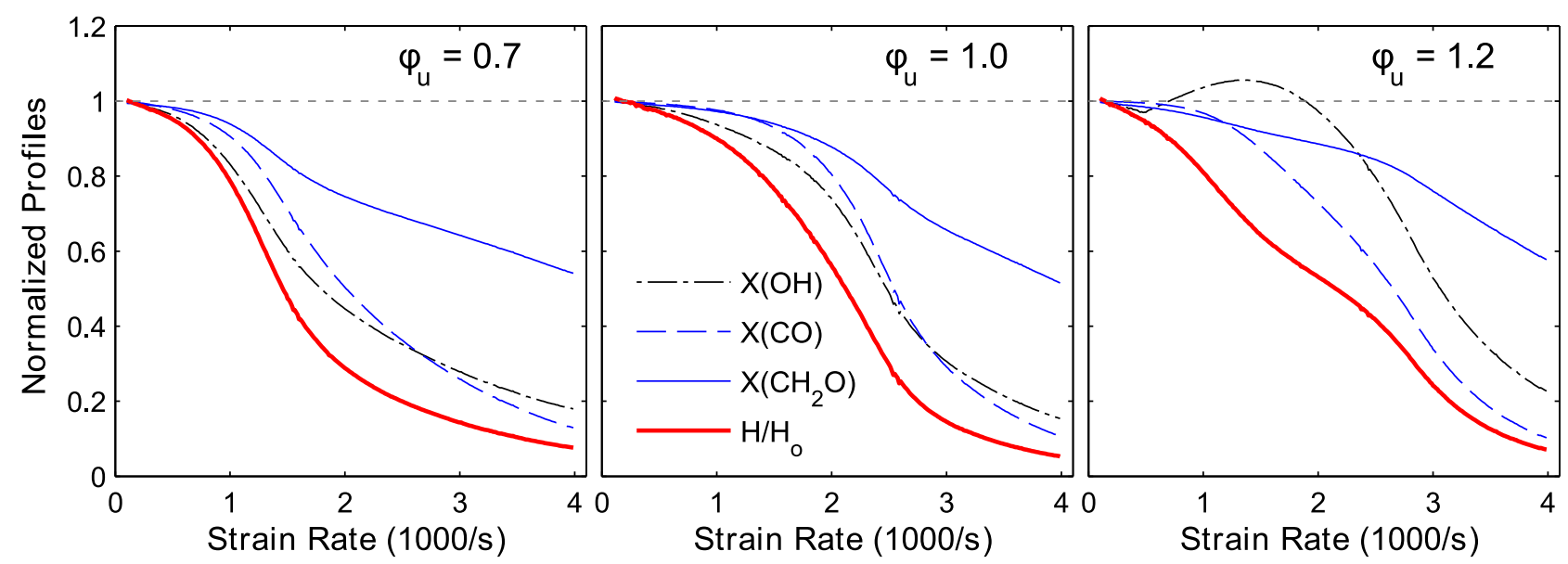

Figure 6 - Normalized $\mathrm{OH}, \mathrm{CO}$ and $\mathrm{CH}_{2} \mathrm{O}$ peak mole fractions and peak heat release rates for $\varphi_{b}=0.7$ and $\varphi_{u}$ equal to $0.7,1.0$ and 1.2 plotted as a function of strain rate computed using a one-dimensional counterflow model. Values are normalized with corresponding ones for unstrained laminar premixed flames.
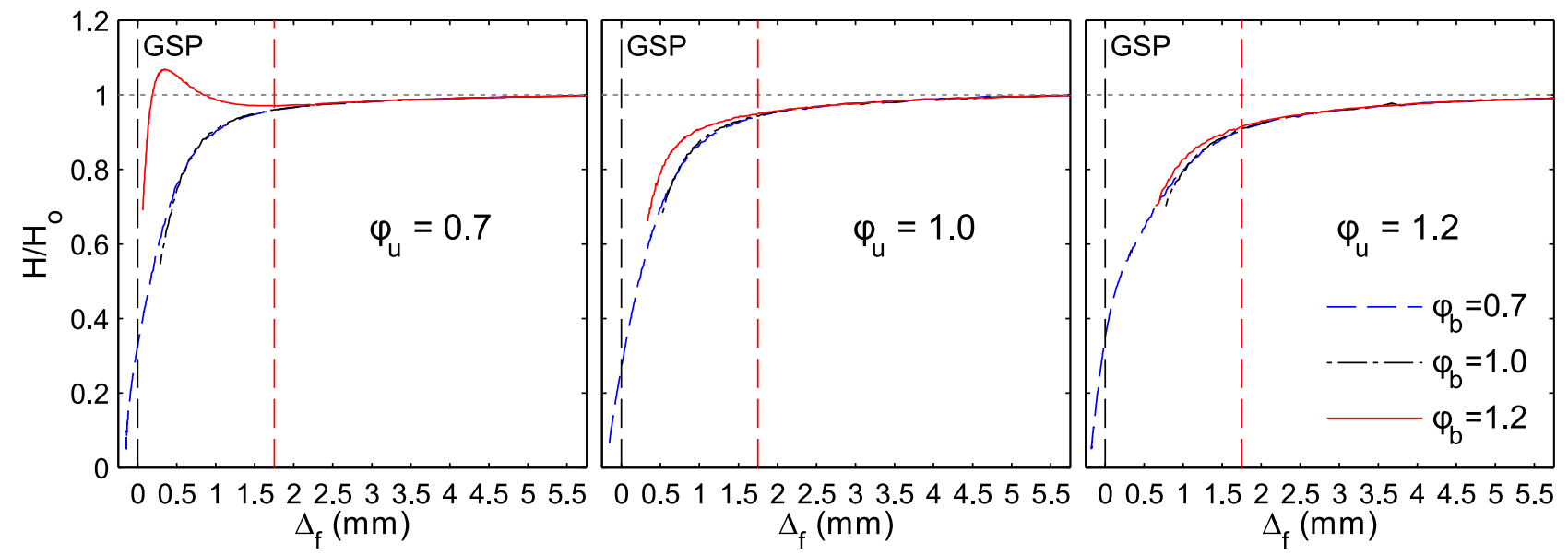

Figure 7 - Computed normalized peak heat release rates to extinction as a function of their position with respect to the gas stagnation plane (GSP), $\Delta_{f}$, for $\varphi_{b}$ equal to $0.7,1.0$ and 1.2 and for $\varphi_{u}=0.7$ (left), $\varphi_{u}=1.0$ (middle) and $\varphi_{u}=1.2$ (right). Values are normalized with corresponding ones for unstrained laminar premixed flames. Vertical red dashed line indicates the approximate boundary of the zone of influence of the product stream. 
Full-length article submitted to Combustion and Flame

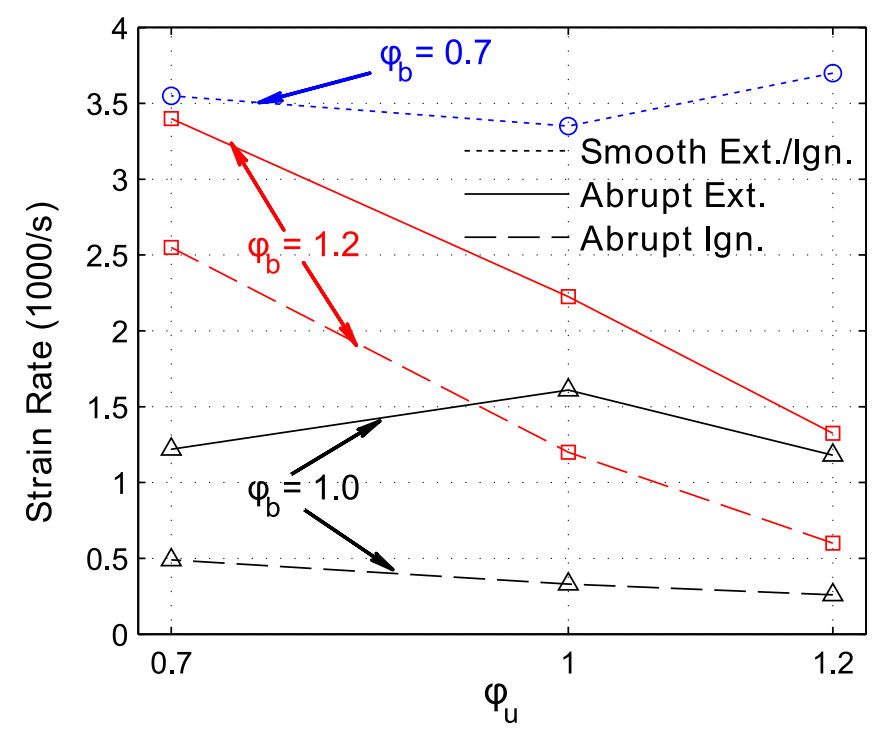

Figure 8 - Computed smooth extinction/ignition (dotted) strain rates and abrupt extinction (solid) and ignition (dashed) strain rates for $\varphi_{u}$ equal to $0.7,1.0$ and 1.2 and for $\varphi_{b}=0.7$ (blue), $\varphi_{b}=1.0$ (black) and $\varphi_{b}=1.2$ (red). Smooth extinction/ignition strain rates correspond to $90 \%$ decrease of peak heat release rates relative to in unstrained laminar flow. 
Full-length article submitted to Combustion and Flame
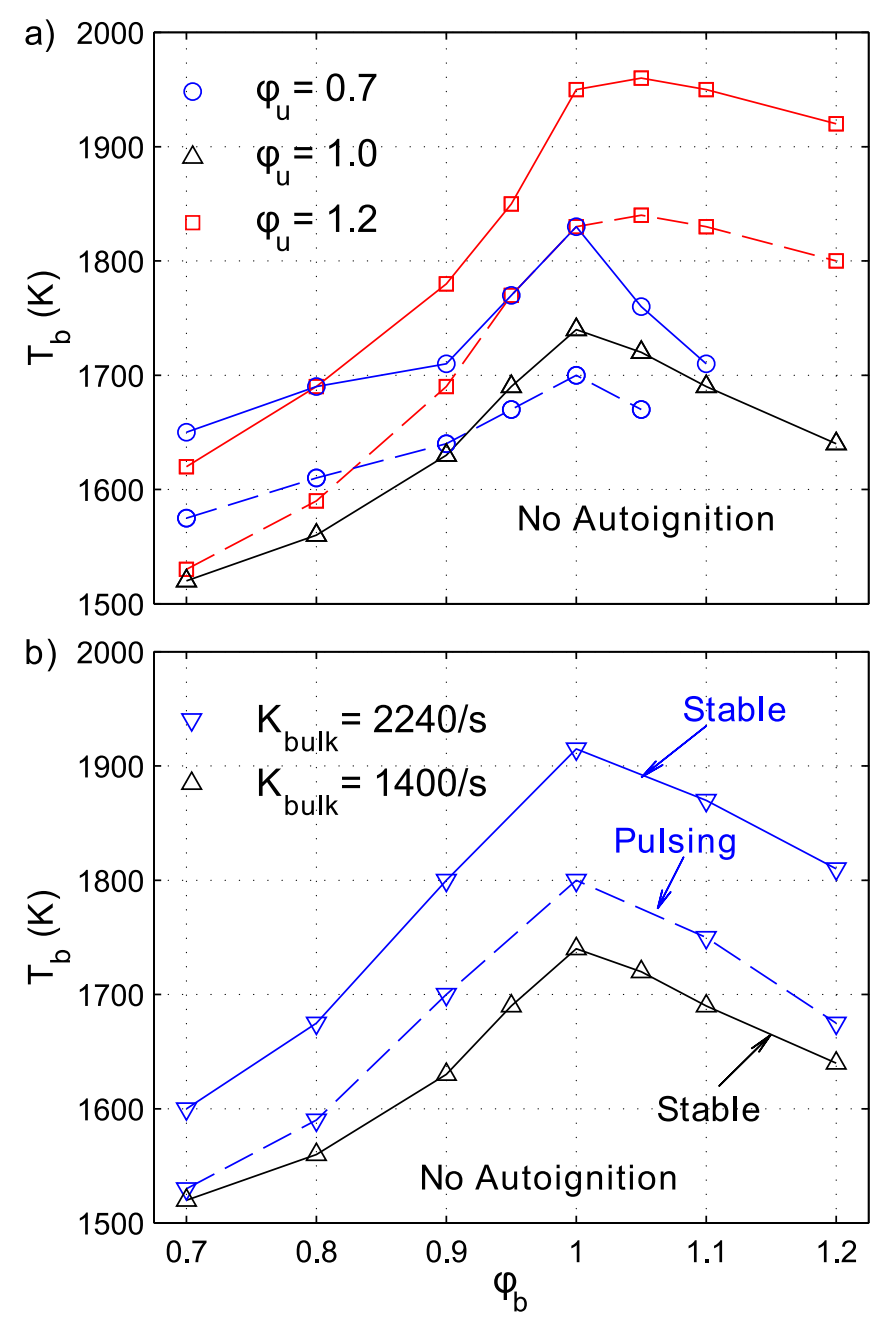

Figure 9 - Ignition and flame stability limits plotted in terms of $T_{b}$ and $\varphi_{b}$ for a) premixed flames of equivalence ratios $\varphi_{u}$ equal to $0.7,1.0$ and 1.2 at $K_{b u l k}=1400 / \mathrm{s}$ and b) the stoichiometric $\left(\varphi_{u}=1.0\right)$ premixed flame at $K_{\text {bulk }}=1400 /$ s and 2240/s. Stable burning regime (solid); pulsing burning regime (dashed). 

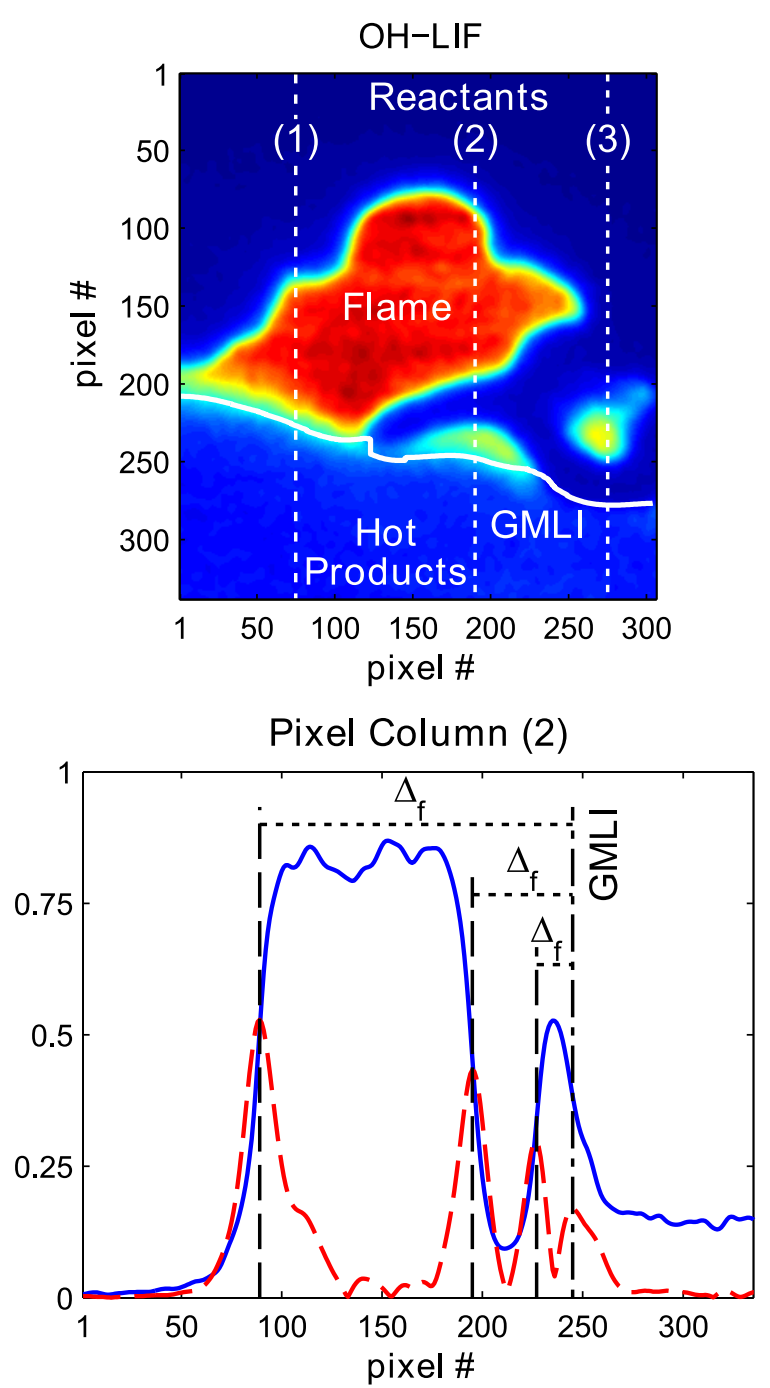
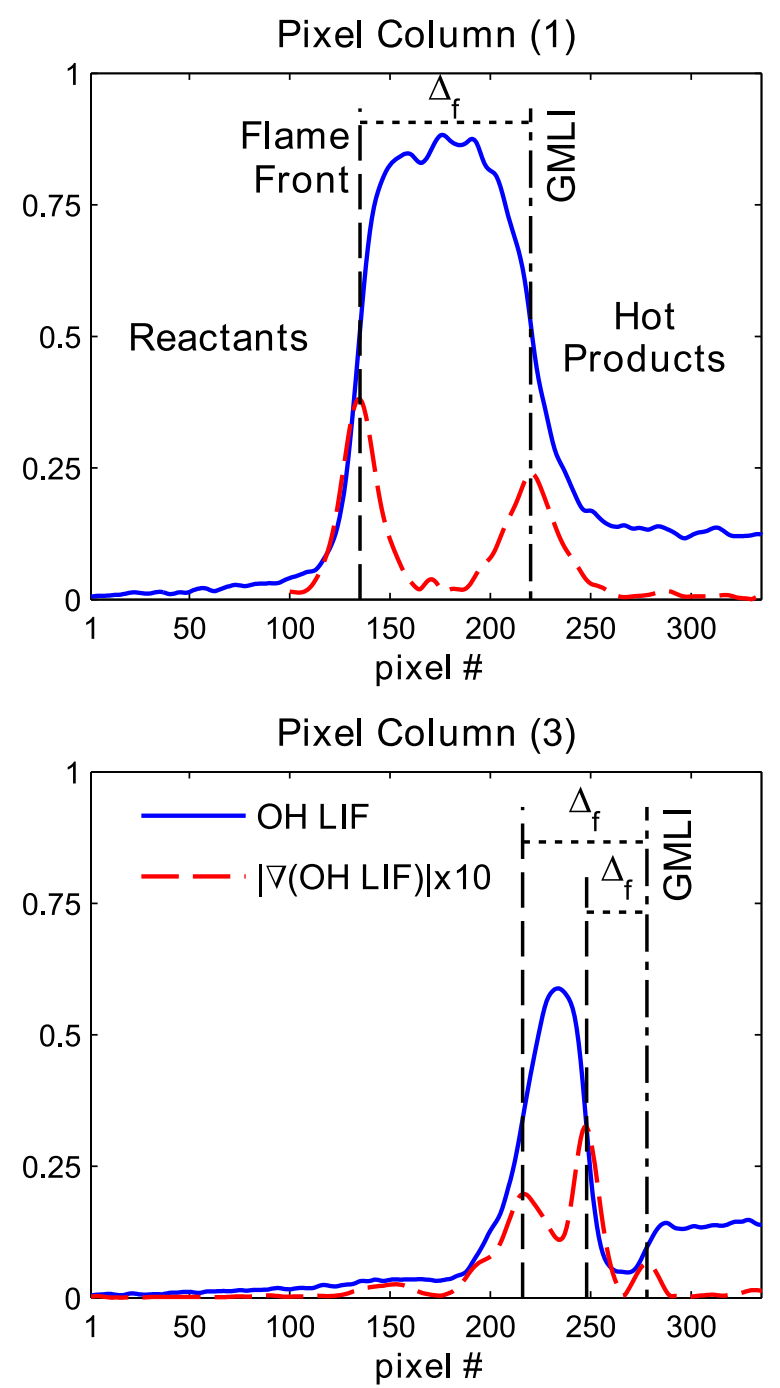

Figure 10 - Definition and identification of the gas mixing layer interface (GMLI) and the flame front location in a single-shot OH LIF measurement. 

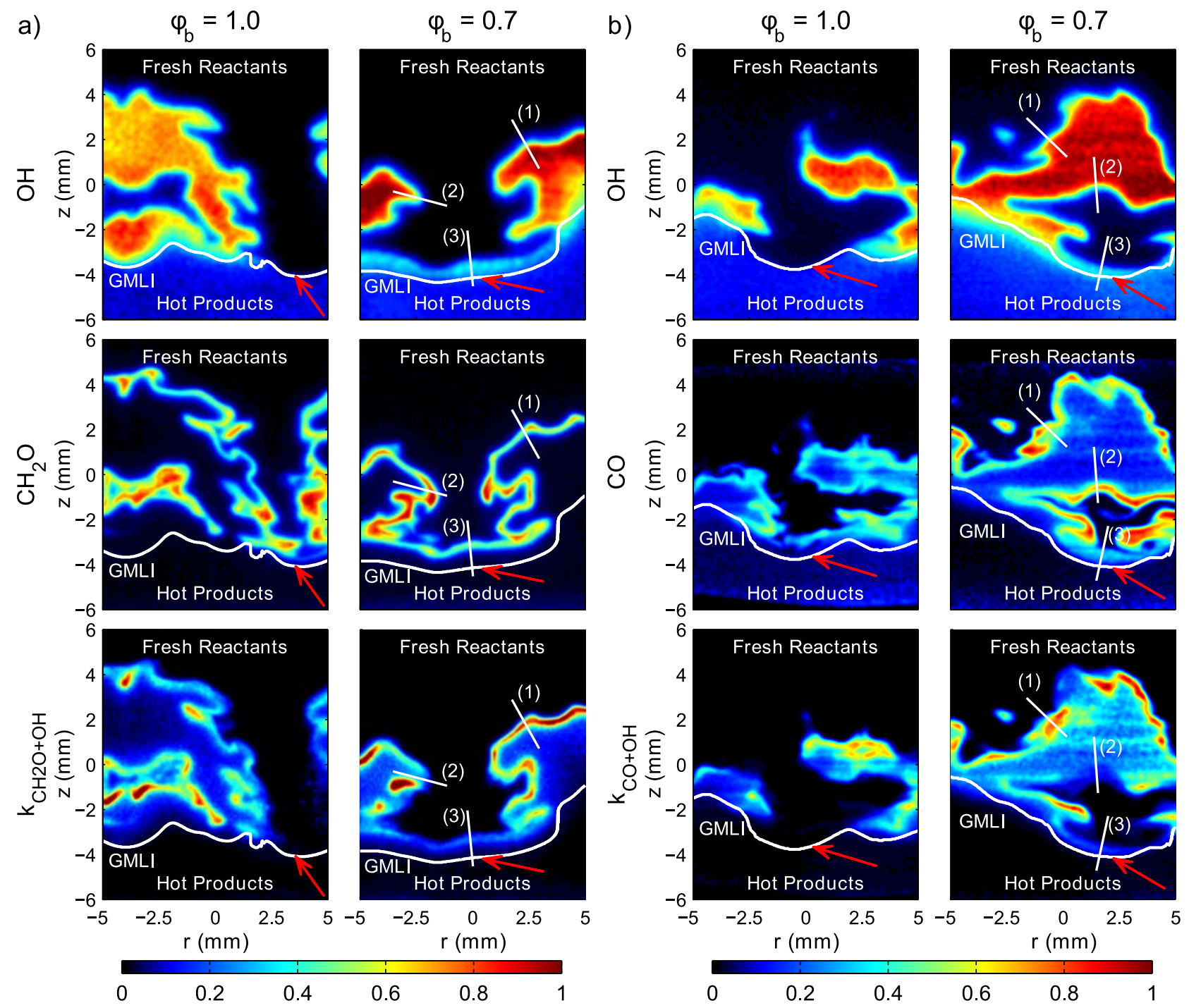

Figure 11- Single-shot LIF measurements in the lean $\left(\varphi_{u}=0.7\right)$ turbulent premixed flame opposed to either stoichiometric $\left(\varphi_{b}=1.0\right)$ or lean $\left(\varphi_{b}=0.7\right)$ products of combustion at $T_{b}=1850 \mathrm{~K}$. a) OHLIF (top row), $\mathrm{CH}_{2} \mathrm{OLIF}$ (middle row), and reaction rate $k_{\mathrm{CH} 2 \mathrm{O}+\mathrm{OH}}$ (bottom row), b) OHLIF (top row), $\mathrm{COLIF}$ (middle row) and reaction rate, $\mathrm{k}_{\mathrm{CO}+\mathrm{OH}}$ (bottom row). Reaction rates, $k_{\mathrm{CH} 2 \mathrm{O}+\mathrm{OH}}$ and $k_{\mathrm{CO}+\mathrm{OH}}$, are indicative of the primary heat release rate and the rate of $\mathrm{CO}$ oxidation in the flame, respectively.Red arrows indicate extinguished or partially extinguished regions along the GMLI. The reaction rates and the LIF signals were normalized with respect to their respective ensemble-averaged values computed for $\Delta_{f} \geq 1.75 \mathrm{~mm}$. 
Full-length article submitted to Combustion and Flame
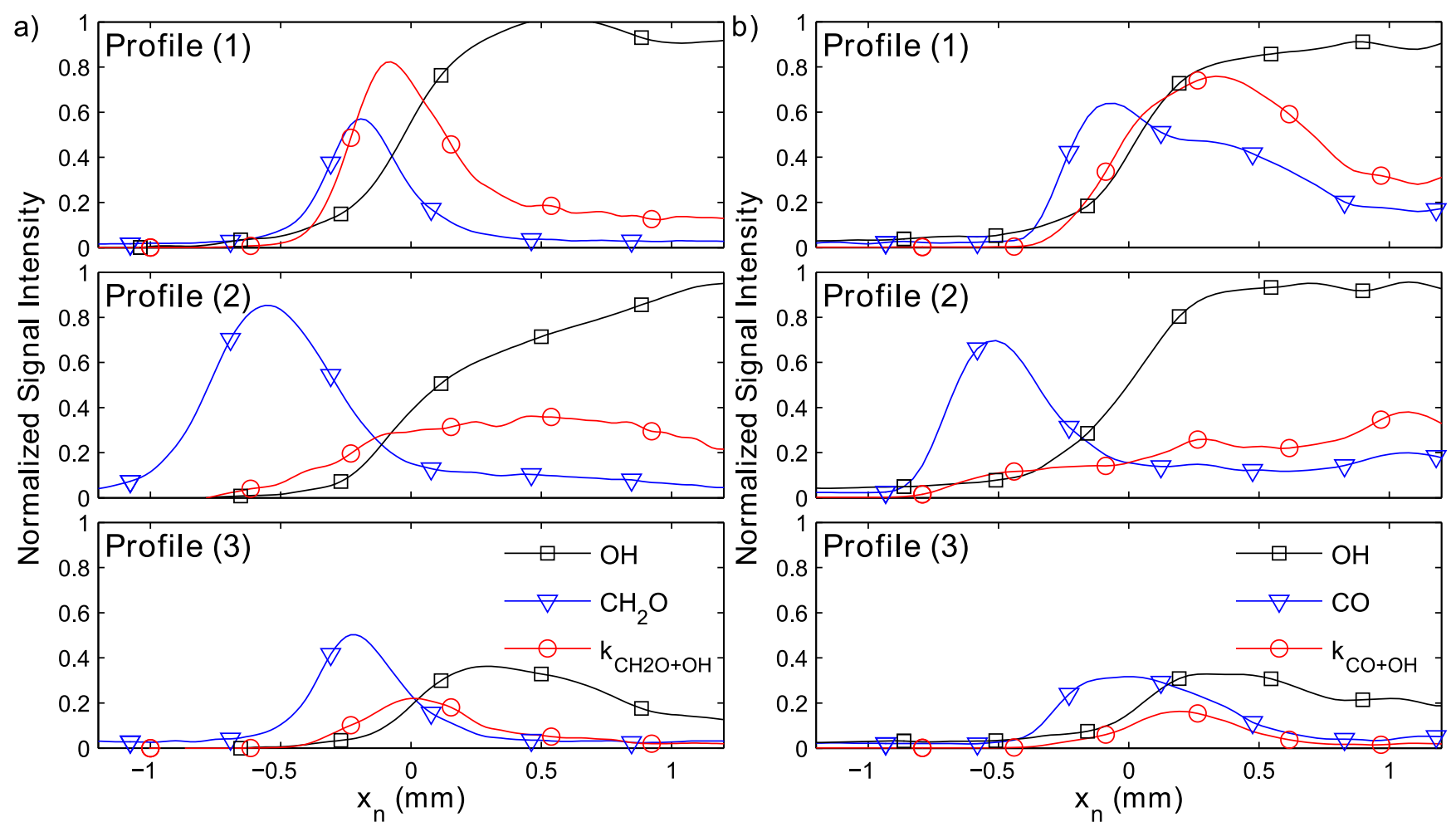

Figure 12 - Flame-normal profiles of a) OHLIF, $\mathrm{CH}_{2} \mathrm{OLIF}$, and $k_{\mathrm{CH} 2 \mathrm{O}+\mathrm{OH}}$ interpolated along segments labeled (1), (2) and (3) in Fig. 11a; b) COLIF, OHLIF and $k_{\mathrm{CO}+\mathrm{OH}}$ for the segments in Fig. 11b.The reaction rates and the LIF signals were normalized with respect to their respective ensemble-averaged values computed for $\Delta_{f} \geq 1.75 \mathrm{~mm}$. 
Full-length article submitted to Combustion and Flame
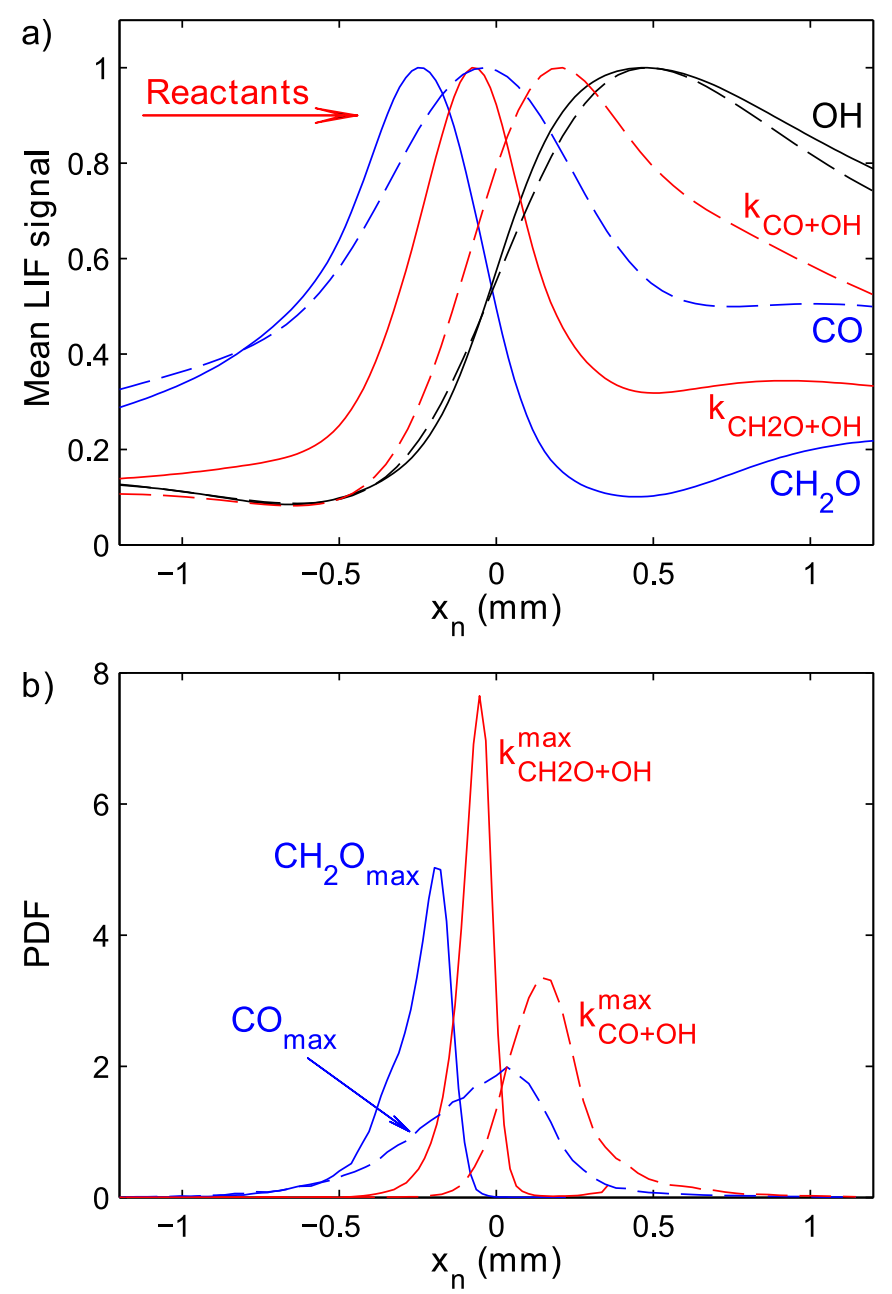

Figure 13 - a) Mean turbulent premixed flame structure $\left(\varphi_{u}=\varphi_{b}=0.7\right)$ based on mean flame-normal profiles of LIF signals of $\mathrm{CH}_{2} \mathrm{O}, \mathrm{OH}$ and forward reaction rate of $\mathrm{CH}_{2} \mathrm{O}+\mathrm{OH}$ (solid lines), as well as LIF signals of $\mathrm{CO}, \mathrm{OH}$ and forward reaction rate of $\mathrm{CO}+\mathrm{OH}$ (dashed lines); b) PDFs of positions of peak $\mathrm{CO}$ LIF, peak $\mathrm{CH}_{2} \mathrm{O}$ LIF and peak reaction rates along the flame-normal coordinate. 
Full-length article submitted to Combustion and Flame
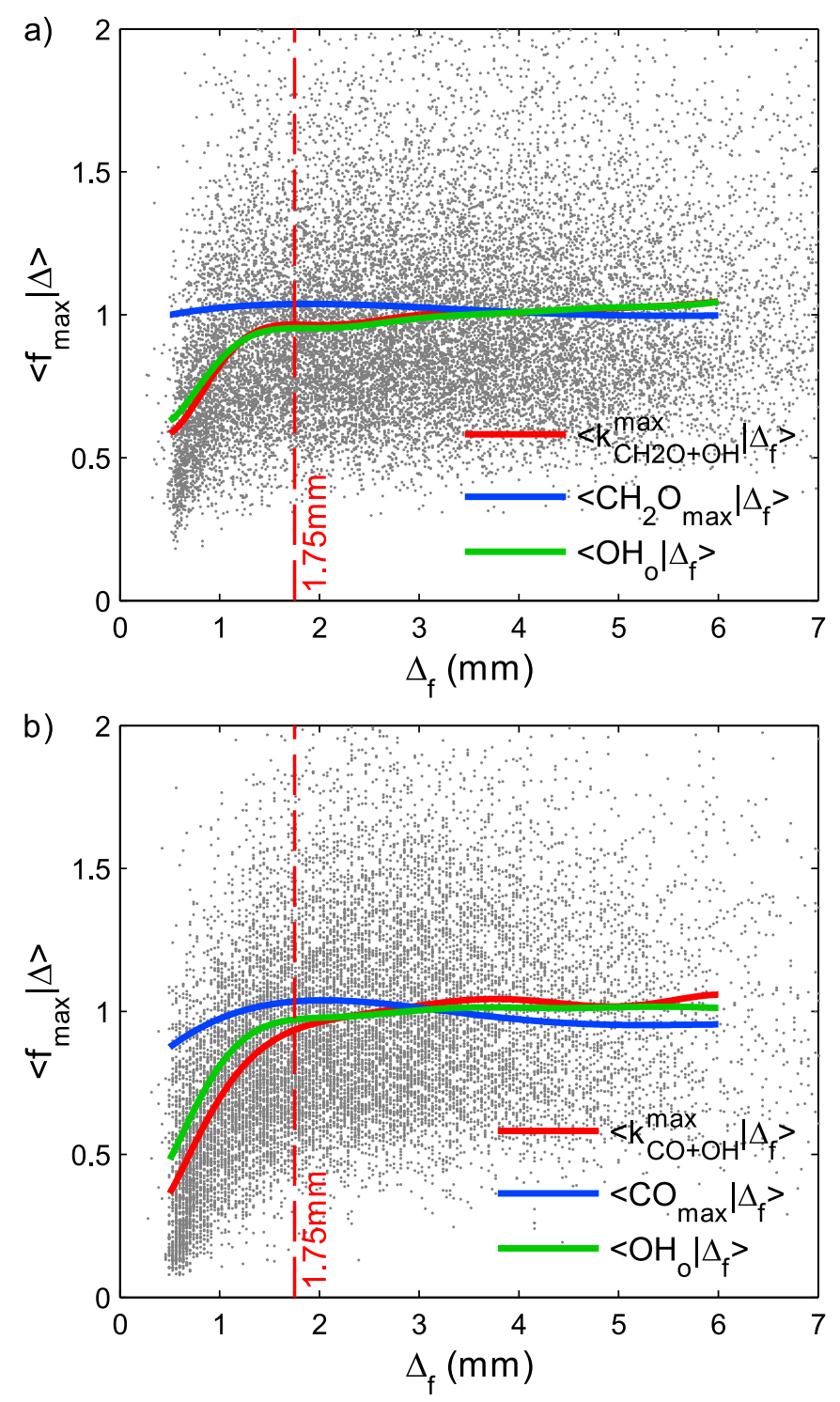

Figure 14 - Scatter plots of normalized values of a) $k_{C H 2 O+O H}^{\max }$ and b) $k_{C O+O H}^{\max }$ as a function of $\Delta_{f}$ for the lean $\left(\varphi_{u}=0.7\right)$ turbulent premixed flame opposed to lean $\left(\varphi_{b}=0.7\right)$ counterflowing combustion products. Scatter plots are overlapped with averages of a) $\mathrm{k}_{\mathrm{CH} 2 \mathrm{O}+\mathrm{OH}}^{\max }$ (red), $\mathrm{CH}_{2} \mathrm{O}_{\max }$ (blue) and $\mathrm{OH}_{\mathrm{O}}$ (green) and b) $k_{\mathrm{CO}+\mathrm{OH}}^{\max }(\mathrm{red}), \mathrm{CO}_{\max }$ (blue) and $\mathrm{OH}_{\mathrm{o}}$ (green), conditioned on $\Delta_{f}$.Vertical red dashed line indicates the approximate boundary of the zone of influence of the product stream. 
Full-length article submitted to Combustion and Flame

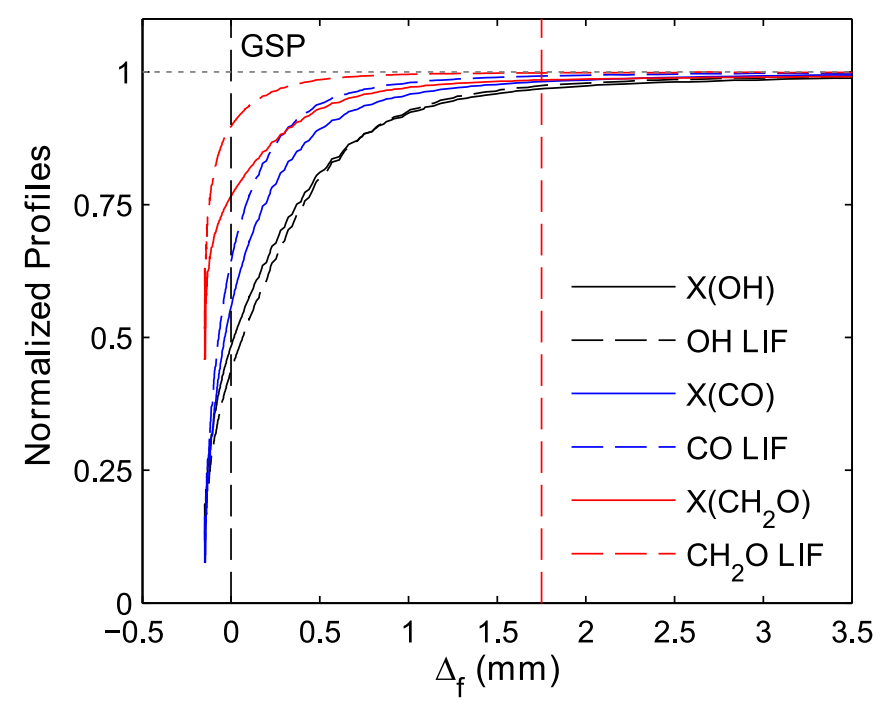

Figure 15 - Comparison of computed normalized peak mole fractions and LIF signals for $\mathrm{OH}, \mathrm{CO}$ and $\mathrm{CH}_{2} \mathrm{O}$ plotted as a function of the location of peak heat release rate with respect to the gas stagnation plane (GSP), $\Delta_{f}$, for $\varphi_{b}=\varphi_{u}=0.7$. Each quantity is normalized by the corresponding value inthe unstrained laminar premixed flame for $\varphi_{u}=0.7$. Vertical red dashed line indicates the approximate boundary of the zone of influence of the product stream. 
Full-length article submitted to Combustion and Flame
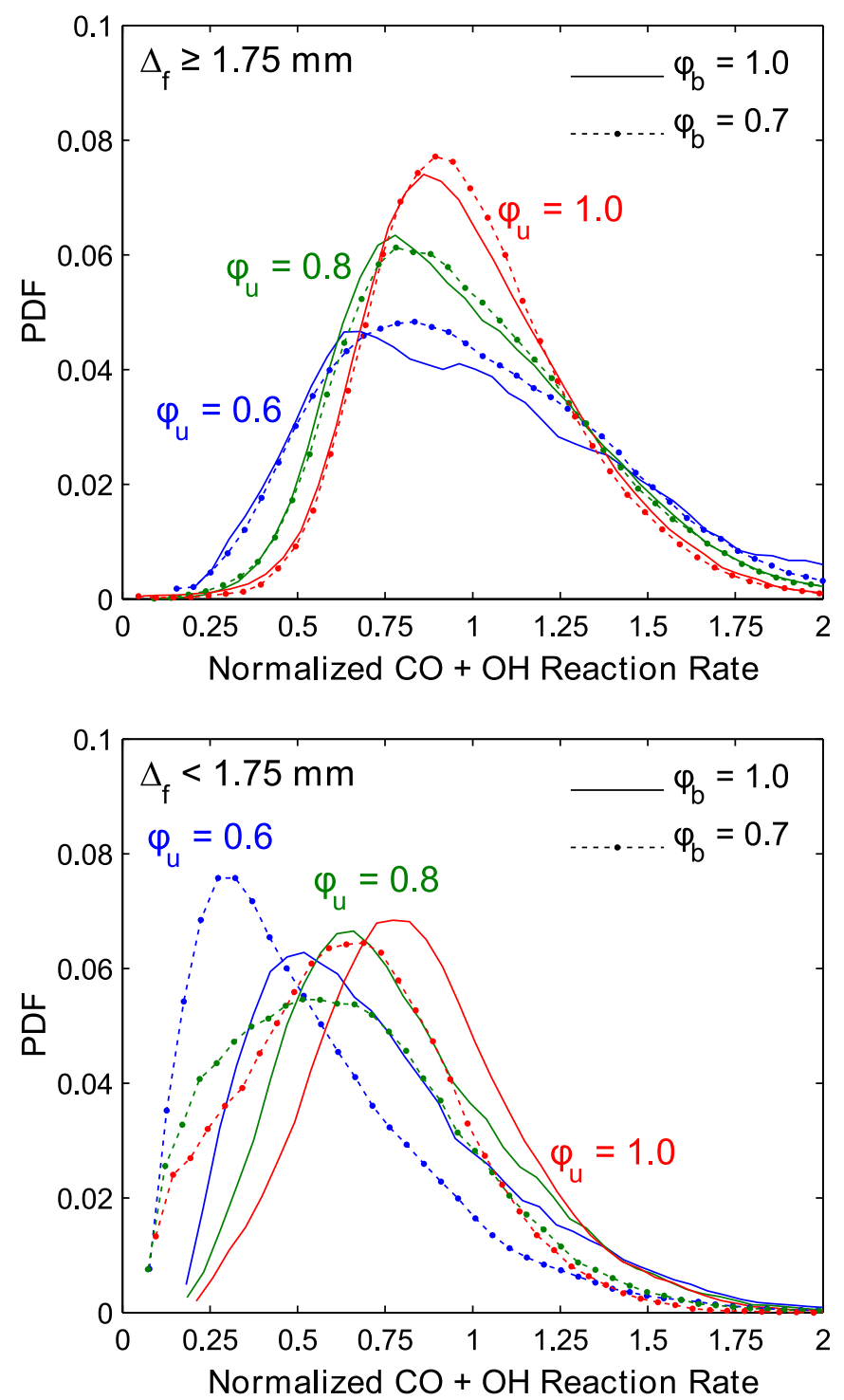

Figure 16- PDFs of $k_{\mathrm{CO}+O H}^{\max }$ for different combinations of reactant and product streams conditioned on the proximity of the turbulent flame fronts to the GMLI: a) $\Delta_{f} \geq 1.75 \mathrm{~mm}$, b) $\Delta_{f}<1.75 \mathrm{~mm}$.For each flame condition, values of $k_{C O+O H}^{\max }$ are normalized with respect to its ensemble-average for $\Delta_{f} \geq 1.75 \mathrm{~mm}$. 
Full-length article submitted to Combustion and Flame

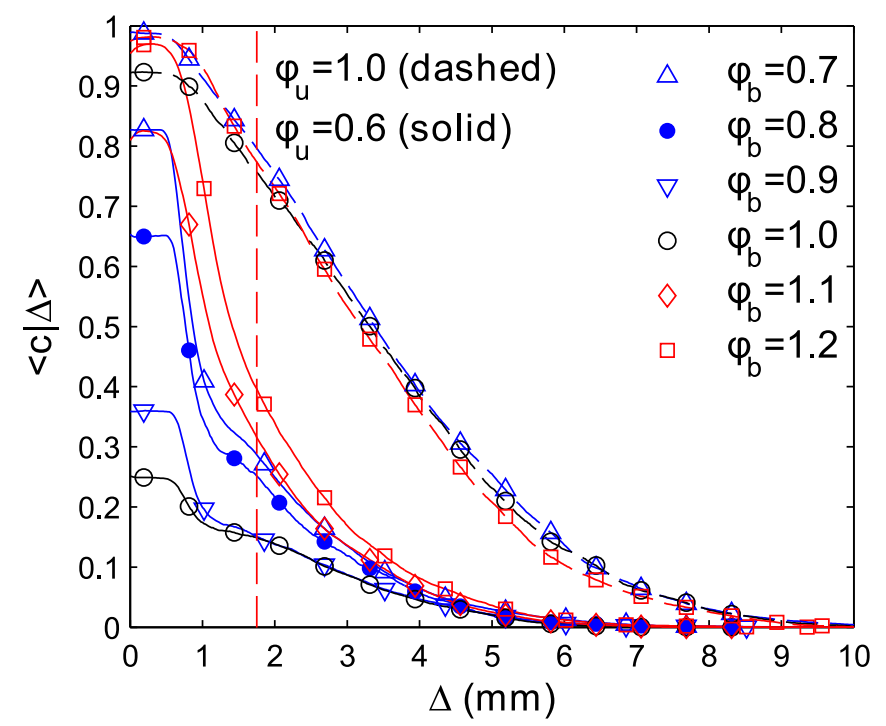

Figure 17 - Effect of productstream equivalence ratio $\varphi_{b}$ on the mean progress variable of turbulent premixed flames of equivalence $\operatorname{ratios} \varphi_{u}=0.6$ (solid lines) and $\varphi_{u}=1.0$ (Dashed lines). Vertical red dashed line indicates the approximate boundary of the zone of influence of the product stream on the reaction rates. 
Full-length article submitted to Combustion and Flame
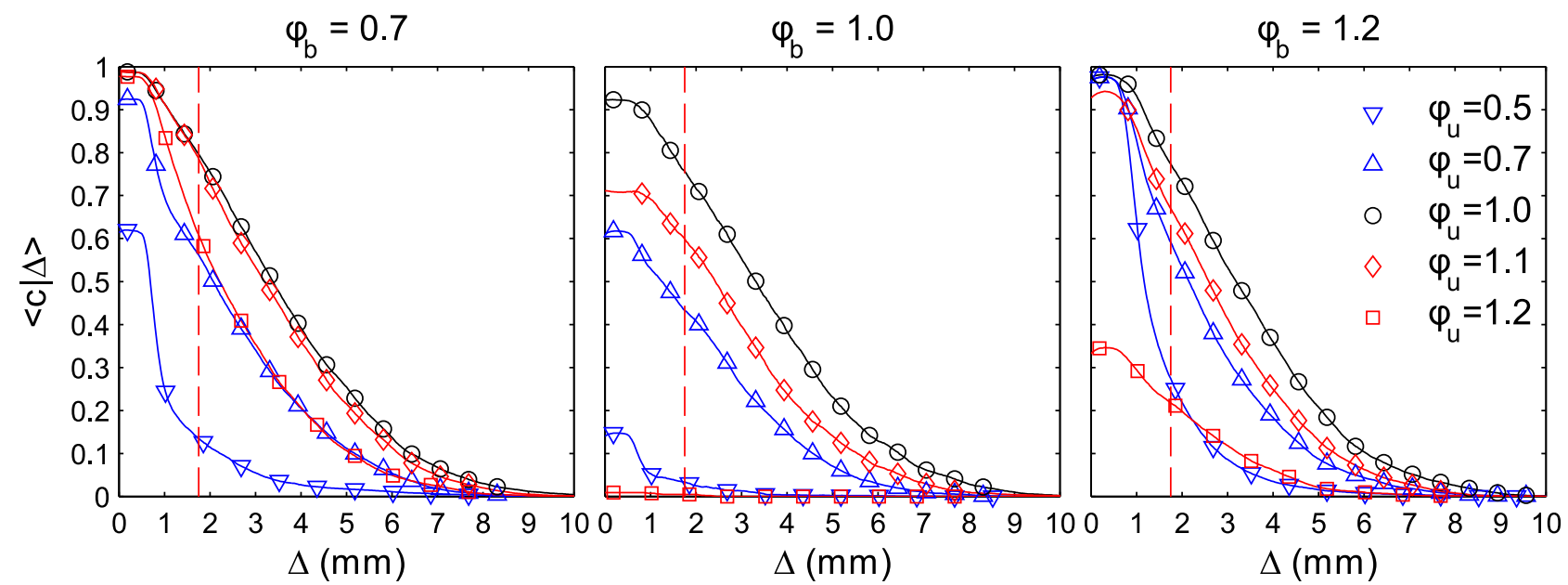

Figure 18 - Effect of product stream equivalence ratio $\varphi_{b}$ on the $\mathrm{OH}$-based mean progress variable of turbulent premixed flames of equivalence ratios $\varphi_{u}$ equal to $0.5,0.7,1.0,1.1$ and 1.2. Vertical red dashed line indicates the approximate boundary of the zone of influence of the product stream on the reaction rates. 